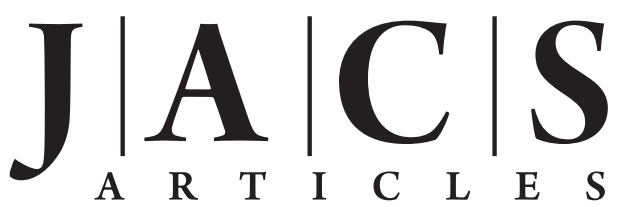

Published on Web 12/18/2008

\title{
Hydroxynaphthyridine-Derived Group III Metal Chelates: Wide Band Gap and Deep Blue Analogues of Green Alq 3 (Tris(8-hydroxyquinolate)aluminum) and Their Versatile Applications for Organic Light-Emitting Diodes
}

\author{
Szu-Hung Liao, ${ }^{\dagger, \ddagger}$ Jin-Ruei Shiu, ${ }^{\dagger,}$ Shun-Wei Liu, ${ }^{\dagger, \|}$ Shi-Jay Yeh, ${ }^{\dagger}$ Yu-Hung Chen," \\ Chin-Ti Chen, ${ }^{*, \dagger, \perp}$ Tahsin J. Chow, ${ }^{*, \dagger}$ and Chih-I Wu${ }^{*, I I}$ \\ Institute of Chemistry, Academia Sinica, Taipei, Taiwan 11529, R.O.C., Department of \\ Chemistry, National Taiwan Normal University, Taipei, Taiwan 11677, R.O.C., Department of \\ Chemistry and Biochemistry, National Chung Cheng University, Chia-Yi, Taiwan 62102, R.O.C., \\ Graduate Institute of Photonics and Optoelectronics and Department of Electrical Engineering, \\ National Taiwan University, Taipei, Taiwan 10617, R.O.C., and Department of Applied \\ Chemistry, National Chiao Tung University, Hsinchu, Taiwan 30050, R.O.C.
}

Received September 20, 2008; E-mail: cchen@ chem.sinica.edu.tw; tjchow@chem.sinica.edu.tw

\begin{abstract}
A series of group III metal chelates have been synthesized and characterized for the versatile application of organic light-emitting diodes (OLEDs). These metal chelates are based on 4-hydroxy-1,5naphthyridine derivates as chelating ligands, and they are the blue version analogues of well-known green fluorophore $\mathrm{Alq}_{3}$ (tris(8-hydroxyquinolinato)aluminum). These chelating ligands and their metal chelates were easily prepared with an improved synthetic method, and they were facially purified by a sublimation process, which enables the materials to be readily available in bulk quantity and facilitates their usage in OLEDs. Unlike most currently known blue analogues of $\mathbf{A l q}_{3}$ or other deep blue materials, metal chelates of 4-hydroxy-1,5-naphthyridine exhibit very deep blue fluorescence, wide band gap energy, high charge carrier mobility, and superior thermal stability. Using a vacuum-thermal-deposition process in the fabrication of OLEDs, we have successfully demonstrated that the application of these unusal hydroxynaphthyridine metal chelates can be very versatile and effective. First, we have solved or alleviated the problem of exciplex formation that took place between the hole-transporting layer and hydroxynaphthyridine metal chelates, of which OLED application has been prohibited to date. Second, these deep blue materials can play various roles in OLED application. They can be a highly efficient nondopant deep blue emitter: maximum external quantum efficiency $\eta_{\text {ext }}$ of $4.2 \%$; Commision Internationale de L'Eclairage $x, y$ coordinates, $\mathrm{CIE}_{x, y}=0.15$, 0.07. Compared with $\mathrm{Alq}_{3}, \mathrm{Bebq}_{2}$ (beryllium bis(benzoquinolin-10-olate)), or TPBI $\left(2,2^{\prime}, 2^{\prime \prime}-(1,3,5\right.$-phenylene)tris(1-phenyl-1 $H$-benzimidazole), they are a good electron-transporting material: low $\mathrm{HOMO}$ energy level of $6.4-6.5 \mathrm{eV}$ and not so high LUMO energy level of 3.0-3.3 eV. They can be ambipolar and possess a high electron mobility of $10^{-4} \mathrm{~cm}^{2} / \mathrm{V} \mathrm{s}$ at an electric field of $6.4 \times 10^{5} \mathrm{~V} / \mathrm{cm}$. They are a qualified wide band gap host material for efficient blue perylene $\left(\mathrm{CIE}_{x, y}=0.14,0.17\right.$ and maximum $\left.\eta_{\text {ext }} 3.8 \%\right)$ or deep blue 9,10-diphenylanthracene $\left(\mathrm{CIE}_{x, y}=0.15,0.06\right.$ and maximum $\left.\eta_{\mathrm{ext}} 2.8 \%\right)$. For solid state lighting application, they are desirable as a host material for yellow dopant (rubrene) in achieving high efficiency $\left(\eta_{\text {ext }} 4.3 \%\right.$ and $\eta_{\mathrm{P}} 8.7 \mathrm{Im} / \mathrm{W}$ at an electroluminance of $100 \mathrm{~cd} / \mathrm{m}^{2}$ or $\eta_{\mathrm{ext}} 3.9 \%$ and $\eta_{\mathrm{P}} 5.1 \mathrm{Im} / \mathrm{W}$ at an electroluminance of $\left.1000 \mathrm{~cd} / \mathrm{m}^{2}\right)$ white electroluminescence $\left(\mathrm{ClE}_{x, y}=0.30,0.35\right)$.
\end{abstract}

\section{Introduction}

Efficient electroluminescence (EL) was first reported by Tang and Van Slyke using green light-emitting tris(8-hydroxyquinolinato)aluminum (Alq $\left.\mathbf{A}_{3}\right)^{1}$ Very few materials attract attention as much as $\mathbf{A l q} \mathbf{l}_{3}$ does in organic light-emitting diodes (OLEDs). ${ }^{2}$ $\mathbf{A l q}_{3}$ has been used as a green emitter, a common electrontransporting material, and a host material for saturated green

\footnotetext{
$\dagger^{\dagger}$ Academia Sinica.

National Taiwan Normal University.

\& National Chung Cheng University.

"National Taiwan University.

${ }^{\perp}$ National Chiao Tung University.

(1) Tang, C. W.; Van Slyke, S. A. Appl. Phys. Lett. 1987, 51, 913.

(2) (a) Chen, C. H.; Shi, J. Coord. Chem. Rev. 1998, 171, 161.
}

and red fluorescent dopants. ${ }^{3}$ Moreover, due to the rigid balllike geometry, high glass transition temperature $\left(T_{\mathrm{g}} \sim 175^{\circ} \mathrm{C}\right),{ }^{3 \mathrm{c}}$ and polymorphic nature, ${ }^{4} \mathbf{A l q}_{3}$ is readily sublimed to form amorphous thin films, which is beneficial to the fabrication and operation lifetime of OLEDs. To tune its fluorescence color to

(3) (a) Tang, C. W.; Van Slyke, S. A.; Chen, C. H. J. Appl. Phys. 1989, 65, 3610. (b) Bulovic, V.; Baldo, M. A.; Forrest, S. R. In Organic Electronic Materials: Conjugated Polymers and Low Molecular Weight Organic Solids; Farchioni, R., Grosso, G., Eds.; Springer-Verlag: New York, 2001; p 391. (c) Higginson, K. A.; Thomsen, D. L., III; Yang, B.; Papadimitrakopoulos, F. In Organic Light-Emitting Devices: A Survey; Shinar,J., Ed.; Springer-Verlag: New York, 2004; p 71. (d) Chen, C.-T. Chem. Mater. 2004, 16, 4389.

(4) Brinkmann, M.; Gadret, G.; Muccini, M.; Taliani, C.; Masciocchi, N.; Sironi, A. J. Am. Chem. Soc. 2000, 122, 5147. 
the red or blue region, some structurally modified $\mathbf{A l q}_{3}$ derivatives have been developed in past two decades to match the requirement in the RGB full color display or white light illumination application. However, most structurally modified $\mathbf{A l q}_{3}$ derivatives become less thermally stable and less volatile under reduced pressure. Very often, they fail in the fabrication of OLEDs by a thermal-vacuum-deposition process.

Photophysical and theoretical studies have already provided insight into the electron distribution of the HOMO/LUMO orbitals of $\mathbf{A l q}_{\mathbf{3}} \cdot{ }^{2,5}$ Whereas the highest electron density of LUMO is found on pyridine ring, the electrons of HOMO orbitals are located mostly on the phenoxide side of the ligand. An electron-withdrawing substituent on the para-position of the phenoxide ring will deplete the HOMO electron density lowering energy level of the filled states. Following the same rationale, the substitution of a electron-donating group on the para-position of the pyridine ring will promote the LUMO electron density raising the energy level of the vacant states. Either structural modification results in increasing energy of electrons involved in frontier orbital transition $\left(\pi-\pi^{*}\right)$ and an emission that is blue-shifted relative to that of parent $\mathbf{A l q}_{\mathbf{3}}\left(\lambda_{\max } \mathrm{f}\right.$ $\sim 514 \mathrm{~nm}$ in toluene and 524 in dichloromethane). Although there are several blue or near-blue light-emitting aluminum chelates, $\mathbf{A l q}{ }_{3}$ derivatives showing deep blue fluorescence $\left(\lambda_{\max }{ }^{\mathrm{f}}\right.$ $<450 \mathrm{~nm}$ ) have not been realized yet. ${ }^{2,6}$ Surveying literature, we have found that a methyl substituent on the pyridine moiety or aza (nitrogen) replacement of " $\mathrm{CH}$ " of the phenoxide moiety of $\mathbf{A l q}_{3}$ is most attractive in blue-shifting fluorescence color, preserving the rigid and globular structure and good valtility of parent $\mathbf{A l q}_{\mathbf{3}}$. Examples are tris(4-methyl-8-quinolinato)aluminum $\left(\mathbf{A} \mathbf{I m} \mathbf{Q}_{\mathbf{3}}\right)$ and tris(4-[1,5]naphthyridinolato)aluminum $\left(\mathbf{A I N D}_{\mathbf{3}}\right)$ showing blue-shifted fluorescence at 506 and $440 \mathrm{~nm}$, respectively (Scheme 1). Whereas the greenish $\mathbf{A l m Q}_{3}$ was reported with EL performance, ${ }^{6 \mathrm{c}-\mathrm{f}}$ application of blue $\mathbf{A I N D}_{\mathbf{3}}$ for OLEDs is still literature unknown to date. ${ }^{2}$ Herein, in addition to the 4-hydroxy-1,5-naphthyridine (ND) aluminum chelate, which was efficiently prepared by our improved synthesis, we report the facile synthesis and full characterization of 4-hydroxy-8-methyl1,5-naphthyridine (mND), 2,8-dimethyl-4-hydroxy-1,5-naphthyridine (mmND), and 4-hydroxy-2-phenyl-1,5-naphthyridine (mpND) metal chelates (Scheme 2). For $\mathbf{m N D}$, mmND, and mpND chelating ligands, a whole series of chelates with group III metals (aluminum, gallium, and indium) were also synthesized and characterized. We employ blue-shifting factors of both

(5) (a) Van Slyke, S. A.; Brynn, P. S.; Levecchio, F. V. U.S. Patent No. 5150006, 1992. (b) Burrow, P. E.; Shen, Z.; Bulvoic, V.; McCarty, D. M.; Forrest, S. R.; Cronin, J. A.; Thompson, M. E. J. Appl. Phys. 1996, 79, 7991. (c) Sugimoto, M.; Anzai, M.; Sakanoue, K.; Sakaki, S. Appl. Phys. Lett. 2001, 79, 2348.

(6) (a) Hamada, Y.; Sano, T.; Fujita, M.; Fuji, T.; Nishio, Y.; Shibata, K. Jpn. J. Appl. Phys. 1993, 32, L514. (b) Hopkins, T. A.; Meerholz, K.; Shaheen, S.; Anderson, M. L.; Schmidt, A.; Kippelen, B.; Padias, A. B.; Hall, H. K., Jr.; Peyghambarian, Armstrong, N. R. Chem. Mater. 1996, 8, 344. (c) Kido, J.; Iizumi, Y. Chem. Lett. 1997, 963. (d) Kido, J.; Iizumi, Y. Appl. Phys. Lett. 1998, 73, 2721. (e) Mattoussi, H.; Murata, H.; Merritt, C. D.; Iizumi, Y.; Kido, J. J. Appl. Phys. 1999 86, 2642. (f) Sapochak, L. S.; Padmaperuma, A.; Washton, N.; Endrino, F.; Schmett, G. T.; Marshall, J.; Forgarty, D.; Burrows, P. E.; Forrest, S. R. J. Am. Chem. Soc. 2001, 123, 6300. (g) Yu, J.; Chen, Z.; Sakuratani, Y.; Suzuki, H.; Tokita, M.; Miyata, S. Jpn. J. Appl. Phys 1999, 38, 6762. (h) Pohl, R.; Anzenbacher, P., Jr. Org. Lett. 2003, 5, 2769. (i) Pohl, R.; Montes, V. A.; Shinar, J.; Anzenbacher, P., Jr. J. Org. Chem. 2004, 69, 1723. (j) Montes, V. A.; Li, G.; Pohl, R.; Shinar, J.; Anzenbacher, P., Jr. Adv. Mater. 2004, 16, 2001. (k) Cheng, J.-A.; Chen, C. H. J. Mater. Chem. 2005, 15, 1179. (1) Montes, V. A.; Pohl, R.; Shinar, J.; Anzenbacher, P., Jr. Chem.-Eur. J. 2006, 12, 4523. (m) Pérez-Bolivar, C.; Montes, V. A.; Anzenbacher, P., Jr. Inorg. Chem. 2006, 45, 9610.
Scheme 1. Chemical Structures of $\mathbf{A l q}_{3}, \mathbf{A l m q}_{3}$, and $\mathbf{A I N D}_{3}$

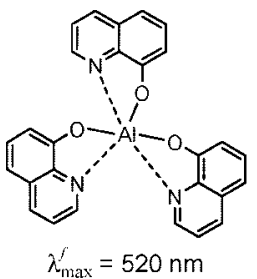

$\mathrm{Alq}_{3}$

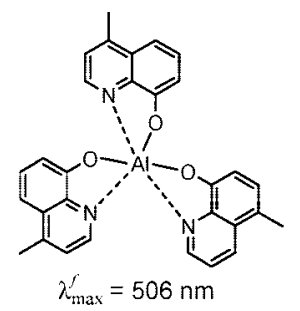

$\mathrm{Almq}_{3}$

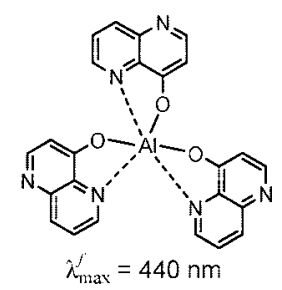

$\mathrm{AIND}_{3}$
Scheme 2. Chemical Structures of Group III Metal Chelates of 8-Hydroxy-1,5-naphthyridine Derivatives

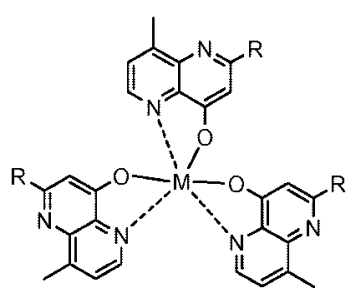

$\mathrm{M}=\mathrm{Al}, \mathrm{R}=\mathrm{H} \quad \mathrm{AImND}_{3}$

$\mathrm{M}=\mathrm{Al}, \mathrm{R}=\mathrm{CH}_{3} \quad \mathrm{AlmmND}_{3}$

$M=A l, R=P h \quad$ AlmpND $_{3}$

$\mathrm{M}=\mathrm{Ga}, \mathrm{R}=\mathrm{H} \quad \mathrm{GamND}_{3}$

$\mathrm{M}=\mathrm{Ga}, \mathrm{R}=\mathrm{CH}_{3} \mathrm{GammND}_{3}$

$M=G a, R=P h \quad G a m p N D_{3}$

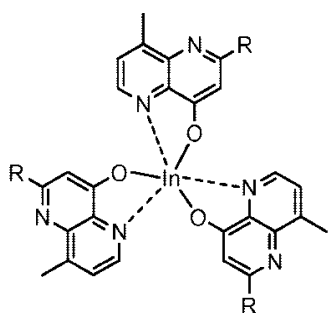

$\mathrm{R}=\mathrm{H}$

$\mathrm{R}=\mathrm{CH}_{3}$

$\mathrm{R}=\mathrm{Ph}$

InmND InmmND InmpND 3 a methyl substituent and aza (nitrogen element) as the replacement of " $\mathrm{CH}$ " in one structure. To our surprise, these metal chelates are in fact new substances and previously unknown. In addition to the thermal stability, they were characterized for deep blue fluorescence and EL in applications of OLEDs. Furthermore, due to their wide band gap and electron-deficient nature, we will demonstrate that these metal chelates are feasible as electron-transporting layer (ETL) material, the host material for highly efficient blue fluorescence dopants, or blue host material for yellow dopants to generate white EL in solid state lighting (SSL) applications.

\section{Results and Discussion}

2.1. Synthesis and Structural Characterization. Parent 4-hydroxy-1,5-naphthyridine (or 1,5-naphthyridin-4-ol) is best known to be prepared by so-called "EMME synthesis" from 3-aminopyridine and diethyl ethoxymethylenemalonate. ${ }^{7}$ After the intramolecular cyclization, the hydrolysis of the resulting ester and thermo-decarboxylation of the acid afford 4-hydroxy-1,5naphthyridine in unsatisfactory overall yields $(18-31 \%){ }^{8}$ Alternatively, a shorter and more convenient procedure known as the Cassis method in the synthesis of a wide range of 4-1Hquinolones (tautomeric forms of hydroxyquinoline) is using

(7) Paudler, W. W.; Kress, T. J. Adv. Heterocycl. Chem. 1970, 11, 123.

(8) Eck, T. D.; Wehry, E. L., Jr.; Hercules, D. M. J. Inorg. Nucl. Chem. 1966, 28, 2439.

(9) (a) Cassis, R.; Tapia, R.; Valderrama, J. A. Synth. Commun. 1985, 15, 125. (b) Chen, B.; Hung, X.; Wang, J. Synthesis 1987, 482. (c) Singh, B.; Laskowski, S. C.; Lesher, G. Y. Synlett 1990, 549. (d) Marcos, A.; Pedregel, C.; Avendaǒo, C. Tetrahedron 1994, 50, 12941. (e) Bontemps, N.; Delfourne, E.; Batide, J.; Francisco, C.; Bracher, F. Tetrahedron 1997, 53, 1743. (f) Kitahara, Y.; Nakahara, S.; Yonezawa, T.; Nagatsu, M.; Shibano, Y.; Kubo, A. Tetrahedron 1997, 53, 17029. (g) Jeon, M.-K.; Kim, K. Tetrahedron Lett. 2000, 41, 1943. (h) Salon, J.; Milata, V.; Pronayova, N.; Lesko, J. Monatch Chem. 2000, 131, 293. 
Scheme 3. Synthetic Routes to a Series of 8-Hydroxy-1,5-naphthyridine Metal Chelates

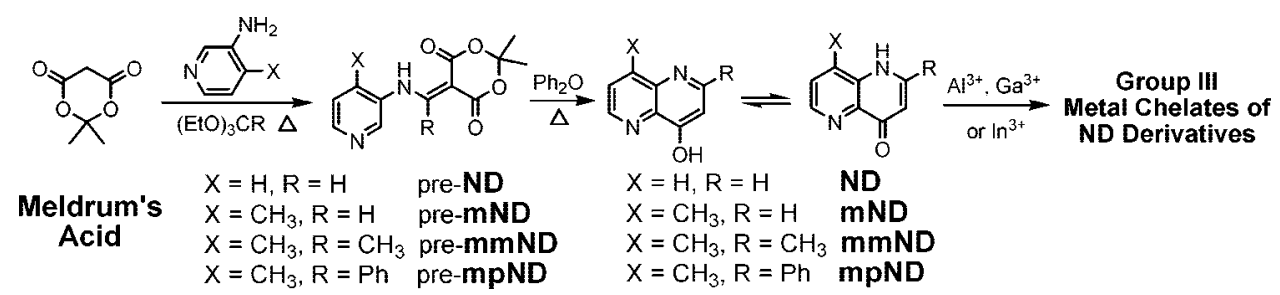

2,2,6-trimethyl-4H-1,3-dioxin-4-one (Meldrum's acid) as an effective diketone equivalent precursor. ${ }^{9}$ Therefore, we adopted the effective Cassis method in the synthesis of the new naphthyrine derivatives, $\mathbf{m N D}$, mmND, and mpND (Scheme 3 ). For comparison purposes in the study herein, parent chelating ligand ND was also synthesized by the more convenient Cassis method.

In the first step of synthesis, four pyridylaminomethylene Meldrum's acid derivatives (pre-ND, pre-mND, pre-mmND, pre-mpND) were all obtained in reasonably good yields, 87, 78, 71, and 58\%, respectively. Among four species, relatively low yields $(58 \%)$ of pre-mpND can be attributed to the bulky phenyl group that causes sterical hindrance in the formation of the methylene-bridge-head between the amino substituent and Meldrum's acid. In the following step of a ring closure reaction, heating Meldrum's acid derivatives in diphenyl ether afforded ND, mND, mmND, and $\mathbf{m p N D}$ in 47-77\% yields, respectively. Among them, ND (1,5-naphthyridin-4-ol or 8-hydroxy-1,5naphthyridine) was obtained in lowest yields $(47 \%)$, and it is due to formation of an undesired structural isomer (1,7naphthyridin-4-ol) in the ring closure reaction. The same cause is believed to occur in the previous "EMME synthesis" of ND, which was prepared in even lower yields. ${ }^{8}$ Nevertheless, the methyl or phenyl substituents of $\mathbf{m N D}, \mathbf{m m N D}$, or $\mathbf{m p N D}$ are simply from the starting materials of either 3-amino-4-picoline or triethyl orthoacetate/orthobenzoate. A different alkyl group or substituted aromatic ring can be readily incorporated onto ND with appropriate starting materials. Through the case of ND, it is conceivable that the Cassis method illustrated herein is more convenient and versatile. From the Cassis method, we obtained ND in $\sim 40 \%$ overall synthetic yields, which is in fact better than $18-31 \%$ overall synthetic yields from the literature reported "EMME synthesis". 8 Moreover, the advantage of the Cassis method is the simpler and more reliable synthetic operation, a two-step procedure instead of a four-step procedure. In "EMME synthesis", a tedious purification process has to be performed four times after each step in the synthetic sequence. The newly synthesized 4-hydroxy-1,5-naphthyridine derivatives were successfully converted into group III metal chelates. However, due to the different reactivity of the metal starting material and the different solubility of the metal chelate product, various reaction conditions and the isolation/purification method were adopted in the final metal chelation reactions, which is somewhat variant from the conventional method preparing $\mathbf{A l q}_{\mathbf{3}}$ (see Experimental Section for details). Basically, the synthesis and purification of hydroxynaphthyridine group III metal chelates are not much difficult than those for the easily prepared and purified Alqu. They can be readily obtained with volume production in a conventional synthetic laboratory.

These metal chelates were fully characterized by ${ }^{1} \mathrm{H}$ and ${ }^{13} \mathrm{C}$ NMR, mass spectroscopy, and elemental analysis, and they were consistent with proposed structures. Particularly, a single crystal X-ray structure of $\mathbf{A I N D}_{\mathbf{3}}$ was obtained. Its ORTEP drawing is displayed in Figure $1 .{ }^{10}$ Similar to that of $\mathbf{A l q} \mathbf{q}_{3}$, the meridional (mer) configuration of $\mathbf{A l N D}_{\mathbf{3}}$ is clearly evident by the structure diagram and it is consistent with its complicated ${ }^{1} \mathrm{H}$ NMR spectrum. Interestingly, unlike $\mathbf{A l m N D}_{\mathbf{3}}$ or $\mathbf{G a m N D}_{\mathbf{3}}, \mathbf{I n m N D _ { 3 }}$ exhibited a simple ${ }^{1} \mathrm{H}$ NMR spectrum (four sharp and wellseparated proton resonances), an indication of the facial (fac) configuration of $\mathbf{I n m N D}_{\mathbf{3}}$. However, recent evidence has demonstrated that the simple ${ }^{1} \mathrm{H}$ NMR spectrum of $\mathbf{I n q} \mathbf{q}_{3}$ (and hence $\mathbf{I n m N D}$ ) is due to the rapid fluxional transitions between mer and fac configurations on the NMR time scale. ${ }^{11}$

The higher level of electron deficiency of ND than 8-hydroxyquinoline is evident by the significantly smaller $\mathrm{p} K_{\mathrm{a}} 2.85$ of ND than $\mathrm{p} K_{\mathrm{a}} 5.13$ of 8-hydroxyquinoline. ${ }^{12} \mathrm{ND}$ derivatives have been known for keto-enol tautomerism in polar organic solvents (see Scheme 3). ${ }^{7}$ We found that the extent of naphthyridone tautomeric forms (and hence the $\mathrm{p} K_{\mathrm{a}}$ value) can be gauged by the ${ }^{1} \mathrm{H}$ NMR signal (chemical shift) of the proton next to the hydroxy substituent of 8-hydroxyquinoline, ND, and $\mathbf{m N D}$, which locates at 7.09, 6.52, and $6.50 \mathrm{ppm}$, respectively (see Figure 2). We expect that even smaller $\mathrm{p} K_{\mathrm{a}}$ values are present for $\mathbf{m m N D}$ and $\mathbf{m p N D}$. The smaller $\mathrm{p} K_{\mathrm{a}}$ values (due to the electron deficiency) render ND derivatives weaker $\delta$-donors on the phenoxide side of the chelating ligand. As the result of a weaker $\delta$-donor, the average $\mathrm{Al}-\mathrm{O}$ bond distance of $\mathbf{A l N D}_{\mathbf{3}}$ $(1.867 \pm 0.03 \AA)$ is longer than that $(1.856 \pm 0.02 \AA)$ of $\mathbf{A l q} \mathbf{q}_{3}{ }^{4}$ On the pyridine side of the chelating ligand, the average $\mathrm{Al}-\mathrm{N}$ bond distance of $\mathbf{A I N D}_{\mathbf{3}}(2.025 \pm 0.03 \AA)$ is shorter than that $(2.051 \pm 0.02 \AA)$ of $\mathbf{A l q} \mathbf{q}_{3}$, and this can be attributed to the "seesaw-like" binding mode of a bidentate chelating ligand. Otherwise, it can be attributed to the stronger $\mathrm{N} \delta$-donor in $\mathbf{A l N D}_{\mathbf{3}}$ than in $\mathbf{A l q}_{\mathbf{3}}$ because of the electron-donating methyl substituent para to the $\mathrm{N} \delta$-donor. We believe that the strength of the $\delta$-donor (or the electron deficiency) of chelating ligands is one of the reasons why aluminum metal chelates of $\mathbf{m N D}$, mmND, or mpND all have a shorter fluorescence peak wavelength and are better in blue color purity than $\mathbf{A I N D}_{\mathbf{3}}$ or $\mathbf{A l q}_{3}$ (see Table 1 for fluorescence data).

2.2. Photophysical Properties and Energy Levels. Whereas it is the desired deep blue color $\left(\lambda_{\max }{ }^{\mathrm{fl}} 415-417 \mathrm{~nm}\right)$ of $\mathbf{A l m N D}_{\mathbf{3}}, \mathbf{A l m m N D}_{3}$, and $\mathbf{A l m p N D}_{3}$, a less satisfactory sky blue fluorescence $\left(\lambda_{\max }{ }^{\mathrm{fl}} 433 \mathrm{~nm}\right)$ of the previously known $\mathbf{A I N D}_{\mathbf{3}}$ is clearly shown in their solution fluorescence images (see Figure 3 ). In the solid state, all four aluminum chelates display redshifted fluorescence wavelength $\lambda_{\max }{ }^{\mathrm{fl}} 425 \mathrm{~nm}$ (AlmpND $\left.\mathbf{A}_{\mathbf{3}}\right), 431$

(10) Crystal data for $\mathbf{A I N D}_{3} \cdot \mathrm{CH}_{2} \mathrm{Cl}_{2}: \mathrm{C}_{25} \mathrm{H}_{17} \mathrm{AlCl}_{2} \mathrm{~N}_{6} \mathrm{O}_{3}: F w=547.33$, Triclinic, $P \overline{1}, Z=2, F(000)=560$. Cell dimendions: $a=7.9946(7)$ $\AA, b=12.0879(11) \AA, c=13.1153(12) \AA, \alpha=70.346(2)^{\circ}, \beta=$ $82.950(2)^{\circ}, \gamma=84.082(2)^{\circ}, V=1181.98(18) \AA^{3}, 2 \theta_{\max }=50.0^{\circ}, \rho_{\text {cacld }}$ $=1.538 \mathrm{mg} / \mathrm{m}^{3}$. Of 8777 reflections, 4157 were independent, 334 parameters, $R\left(F_{\mathrm{o}}\right)=0.0588$ (for reflections with $\left.I>2 \sigma(I)\right), R_{\mathrm{w}}\left(F_{\mathrm{o}}\right)=$ 0.1663 (for reflections with $I>2 \sigma(I)$ ). The GoF on $F^{2}$ was 0.977 .

(11) Sapnochak, L. S.; Ranasinghe, A.; Kohlmann, H.; Ferris, K. F.; Burrows, P. E. Chem. Mater. 2004, 16, 401.

(12) Mason, S. F. J. Chem. Soc. 1957, 5010. 


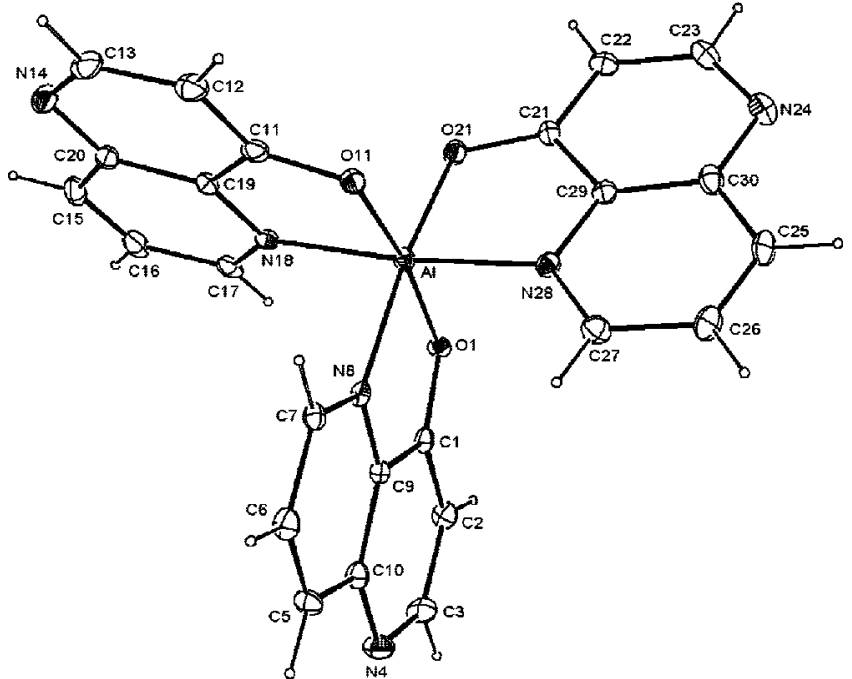

Figure 1. Molecular structure of $\mathbf{A I N D}_{3}$ determined by $\mathrm{X}$-ray diffraction analysis.

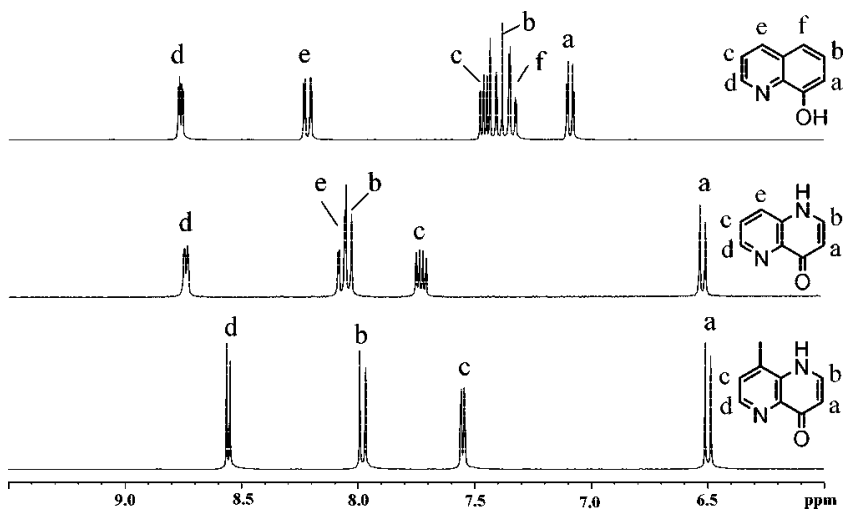

Figure 2. ${ }^{1} \mathrm{H}$ NMR spectra of 8-hydroxyquinoline, ND, and $\mathbf{m N D}$ in $\mathrm{CD}_{3} \mathrm{OD}$ from top to bottom, respectively.

Table 1. Optical and Thermal Properties of Metal Chelates of 4-Hydroxy-1,5-naphthyridine Derivatives

\begin{tabular}{|c|c|c|c|c|c|c|c|c|c|}
\hline \multirow[b]{2}{*}{ metal chelates } & \multicolumn{3}{|c|}{ solution ${ }^{a}$} & \multicolumn{2}{|c|}{ solid } & \multirow[b]{2}{*}{$\begin{array}{c}T_{g} \\
\left({ }^{\circ} \mathrm{C}\right)\end{array}$} & \multirow[b]{2}{*}{$\begin{array}{c}T_{c} \\
\left({ }^{\circ} \mathrm{C}\right)\end{array}$} & \multirow[b]{2}{*}{$\begin{array}{c}T_{\mathrm{m}} \\
\left({ }^{\circ} \mathrm{C}\right)\end{array}$} & \multirow[b]{2}{*}{$\begin{array}{l}\text { LUMO/HOMO } \\
(\mathrm{eV})^{b}\end{array}$} \\
\hline & $\begin{array}{c}\lambda_{\max }{ }^{\mathrm{ab}}, \lambda_{\text {on set }}{ }^{\mathrm{ab}} \\
(\mathrm{nm})\end{array}$ & $\begin{array}{l}\lambda_{\max }^{f l} \\
(n m)\end{array}$ & $\begin{array}{l}\Phi_{f} \\
(\%)\end{array}$ & $\begin{array}{l}\lambda_{\max }{ }^{f l} \\
(\mathrm{~nm})\end{array}$ & $\begin{array}{l}\Phi_{f} \\
(\%)\end{array}$ & & & & \\
\hline $\mathrm{Alq}_{3}$ & 388,443 & 524 & 20 & 516 & 40 & 174 & 367 & 412 & $3.1 / 5.9$ \\
\hline $\mathrm{AlND}_{3}$ & 341,381 & 433 & 47 & 447 & 45 & 122 & 262 & 412 & - \\
\hline $\mathrm{AlmND}_{3}$ & 338,370 & 415 & 45 & 431 & 43 & 196 & $\begin{array}{l}277 \\
387\end{array}$ & 420 & $3.0 / 6.4$ \\
\hline $\mathrm{AlmmND}_{3}$ & 335,372 & 416 & 45 & 419 & 39 & 233 & $c$ & 436 & - \\
\hline $\mathrm{AlmpND}_{3}$ & 326,376 & 417 & 45 & 425 & 6 & 204 & 278 & 370 & - \\
\hline $\mathrm{GamND}_{3}$ & 341,374 & 431 & 45 & 439 & 41 & $c$ & 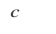 & 414 & $3.2 / 6.5$ \\
\hline $\mathrm{GammND}_{3}$ & 339,376 & 432 & 42 & 434 & 52 & 212 & $c$ & 430 & - \\
\hline $\mathrm{GampND}_{3}$ & 327,383 & 432 & 25 & 439 & 11 & 185 & 275 & 381 & - \\
\hline $\mathrm{InmND}_{3}$ & 344,382 & 436 & 37 & 445 & 12 & 183 & & 361 & $3.3 / 6.5$ \\
\hline InmmND $_{3}$ & 332,381 & 437 & 36 & 436 & 22 & 221 & 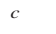 & 372 & - \\
\hline $\operatorname{InmpND}_{3}$ & 329,386 & 437 & 23 & 446 & 8 & 186 & 224 & 370 & - \\
\hline
\end{tabular}

${ }^{a}$ In dichloromethane. ${ }^{b} \mathrm{HOMO}$ energy was determined as the edge of HOMO energy level or the ionization potential of the material; LUMO energy was determined as the lowest photoexcitation state energy from the on-set absorption energy in absorption spectra. ${ }^{c}$ Not observed.

$\mathrm{nm}\left(\mathbf{A l m N D}_{\mathbf{3}}\right)$, and $447 \mathrm{~nm}\left(\mathbf{A l N D}_{\mathbf{3}}\right)$, except $\lambda_{\max }{ }^{\mathrm{fl}} 419 \mathrm{~nm}$ of AlmmND $_{3}$ (Table 1). In dichloromethane solution, all four aluminum chelates have reasonably good fluorescence quantum yields $\left(\Phi_{\mathrm{f}}\right)$ around $45-47 \%$ but more or less suffer from fluorescence concentration quenching in the solid state (Table 1).

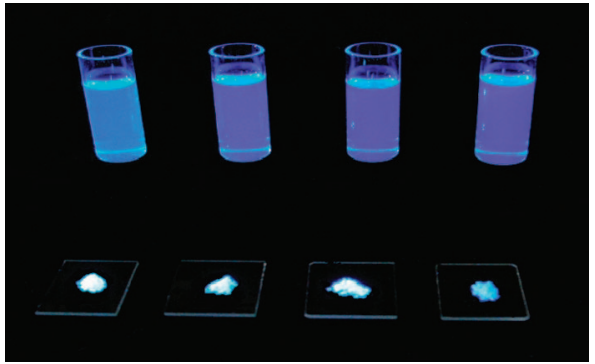

Figure 3. Solution (in dichloromethane) and solid state fluorescence image of $\mathbf{A l N D}_{3}, \mathbf{A l m N D} \mathbf{D}_{3}, \mathbf{A l m m N D}$, and $\mathbf{A l m p N D} \mathbf{D}_{3}$ from left to right, respectively.

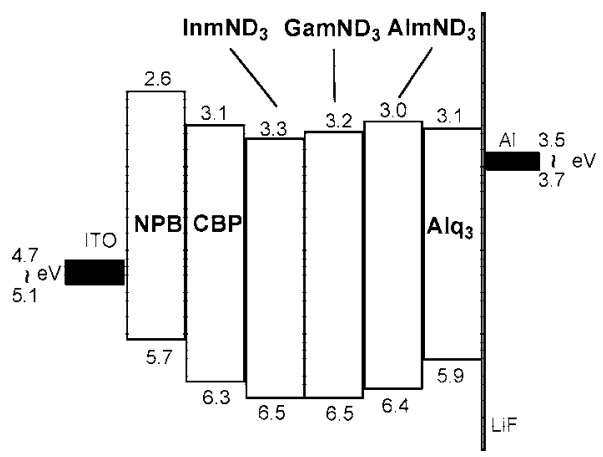

Figure 4. Energy alignment of $\mathrm{AlmND}_{3}, \mathrm{GamND}_{3}, \mathrm{InmND}_{3}, \mathrm{Alq}_{3}, \mathrm{NPB}$, and CBP in OLED devices based on ITO anode and LiF/Al cathode.

Among them, $\mathbf{A l m p N D}_{3}$ has the most severe fluorescence quenching in the solid state with a $\Phi_{\mathrm{f}}$ of only $6 \%$. Such solidstate fluorescence quenching is universal for mpND-based chelates $\left(\mathbf{A l m p N D}_{\mathbf{3}}, \mathbf{G a m p N D}_{\mathbf{3}}\right.$, and $\mathbf{I m m p N D}$. This can be rationalized by the molecular contact (probably $\pi-\pi$ interaction) through protruded phenyl substituents in the solid state. With no exception of the three chelating ligands $\mathbf{m N D}, \mathbf{m m N D}$, and mpND, fluorescence of these metal chelates was observed to be reduced with increasing atomic number of the metal ion from Al to $\mathrm{Ga}$ and then In (see $\Phi_{f}$ data in Table 1), known as the heavy atom effect that increases in the rate of intersystem crossing. ${ }^{2,13}$

In the search for the origin of the wide band gap nature, $\mathbf{A l m N D}_{\mathbf{3}}, \mathbf{G a m N D}_{\mathbf{3}}$, and $\mathbf{I n m N D} \mathbf{n}_{\mathbf{3}}$ were found to have a HOMO energy level around 6.4-6.5 eV, which is significantly lower than $5.9 \mathrm{eV}$ of $\mathbf{A l q}_{\mathbf{3}}$ (Figure 4). The LUMO energy level of three mND metal chelates is around $3.0-3.3 \mathrm{eV}$, which is similar to or just a bit lower than $3.1 \mathrm{eV}$ of $\mathbf{A l q}_{\mathbf{3}}$. This is perfectly logical because the prominent electron deficient feature ( $\mathrm{N}$ aza substituent) locates on the HOMO of the molecule, which is the pyridin-4-olate ring of the chelating ligand, instead of the LUMO of three $\mathbf{m N D}$ metal chelates, which is the paramethylpyridine (or 4-picoline) ring of the chelating ligand. It can be further identified that either HOMO or LUMO is stabilized by the higher atomic number of the central metals, $\mathrm{Al}, \mathrm{Ga}$, and In. Such a stabilization effect happens more prominently in the LUMO than in the HOMO. As a result, the energy band gap of three $\mathbf{m N D}$ metal chelates decreses in the order $\mathbf{A l m N D} \mathbf{Z}_{\mathbf{3}}>\mathbf{G a m N D}_{\mathbf{3}}>\mathbf{I n m N D}$. Relative to that of $\mathbf{A l q}$, a significantly low HOMO energy level and moderately low LUMO energy level enlarge the energy band gap of these hydroxylnaphthyridine-based metal chelates.

(13) Burrow, P. E.; Sapochak, L. S.; McCarty, D. M.; Forrest, S. R.; Thompson, M. E. Appl. Phys. Lett. 1994, 64, 2718. 

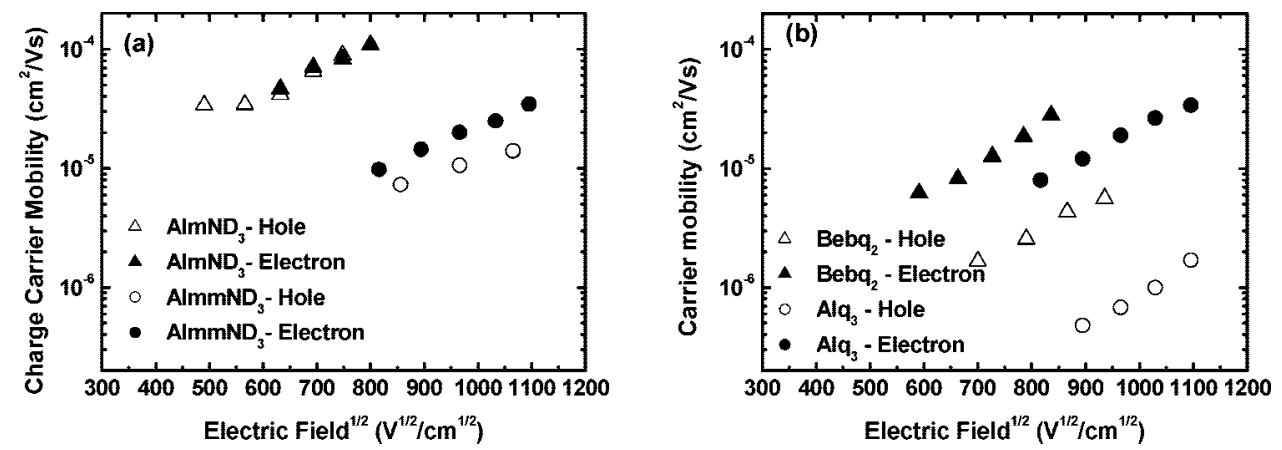

Figure 5. Hole and electron mobility vs the square root of the applied electric field of $\mathbf{A l m N D}_{\mathbf{3}}$ and $\mathbf{A l m m N D}_{\mathbf{3}}$ (a) and $\mathrm{Alq}_{3}$ and $\mathbf{B e b q}_{2}(\mathrm{~b})$.

2.3. Charge-Transporting Properties and Charge Carrier Mobilities. In terms of HOMO and LUMO energy levels, hydroxynaphthyridine-based metal chelates are better holeblocking or electron-transporting materials than $\mathbf{A l q}_{\mathbf{3}}$ or other deep blue fluorophores. Most known deep blue fluorophores are based on triarylamines, such as NPB, or nonheteroatomcontaining polycyclic aromatic hydrocarbons (PAHs), such as anthracene, perylene, pyrene, or spirobifluorene compounds. Compared with those of hydroxynaphthyridine metal chelates, such nonmetal chelate deep blue fluorophores have significantly higher HOMO and LUMO energy levels of 5.1-5.8 eV and 2.0-2.7 eV (assuming band gap energy is ca. $3.1 \mathrm{eV}$ ) below vacuum level, respectively. ${ }^{14}$

The HOMO-LUMO energy level of the material shown above is one of the determining factors for electron-transporting or hole-transporting properties of OLED materials. The charge carrier (electron or hole) mobility is the other decisive characteristic that influences the charge-transporting nature and hence the efficiency performance of OLEDs. The relative magnitude of the electron and hole mobility of the material indicates the extent of charge balancing, the efficiency of charge recombination, and hence the EL efficiency of OLEDs. We measured the intrinsic charge carrier (hole or electron) mobility in a bulk film

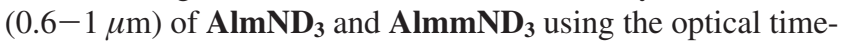
of-flight (TOF) technique that has been described before. In addition, we also took a measurement on $\mathbf{A l q}_{\mathbf{3}}$ and $\mathbf{B e b q}_{2}$ with the same measuring system for comparison and accuracy checking. Figure 5 shows the field dependence of the hole and electron drift mobility of $\mathbf{A l m N D}_{\mathbf{3}}, \mathbf{A l m m N D}_{\mathbf{3}}$ (Figure 5a), Alqu, and $\mathrm{Bebq}_{2}$ (Figure 5b). First, the electron mobility of $\mathbf{A l q} \mathbf{q}_{3}$ was determined to be $\sim 10^{-5} \mathrm{~cm}^{2} / \mathrm{V}$ s at an electric field of $6.4 \times$ $10^{5} \mathrm{~V} / \mathrm{cm}$, which agrees with those obtained previously. ${ }^{15}$ Second, the electron mobility of $\mathrm{Bebq}_{2}$ was determined to be $\sim 10^{-4} \mathrm{~cm}^{2} / \mathrm{V}$ s at the same electric field, which is 1 order of magnitude higher than that of $\mathbf{A l q} \mathbf{q}_{3}$ and consistent with the report that $\mathrm{Bebq}_{2}$ is a better electron-transporting material than $\mathbf{A l q} \mathbf{q}_{3} .{ }^{16}$ Devices with an electron-transporting layer (ETL) of $\mathrm{Bebq}_{2}$ have been demonstrated with lower driving voltage and longer operation lifetime, when compared with ones with $\mathbf{A l q}_{3}$ as an ETL. ${ }^{16}$ Third, we found that the charge carrier (either hole or electron) mobility of $\mathbf{A l m N D}_{\mathbf{3}}$ is higher than that of $\mathbf{A l m m N D}_{\mathbf{3}}$ by nearly 1 order of magnitude (Figure 5a). In fact, checking

(14) Adachi, C.; Oyamada, T. Data Book on HOMO Levels of Organic Thin Films in Organic Semiconductor Devices; CMC Publishing: Tokyo, 2005.

(15) Tse, S. C.; Kwok, K. C.; So, S. K. Appl. Phys. Lett. 2006, 89, 262102.

(16) (a) Lee, J.-H.; Wu, C.-I.; Liu, S.-W.; Huang, C.-A.; Chang, Y. Appl. Phys. Lett. 2005, 86, 103506. (b) Lee, J.-H.; Ho, Y.-H.; Lin, T.-C.; Wu, C.-F. J. Electrochem. Soc. 2007, 154, J226. the extrapolated data in the range of electric field of (3.6-6.4) $\times 10^{5} \mathrm{~V} / \mathrm{cm}$, the charge carrier (either hole or electron) mobility of $\mathbf{A l m N D}_{3}$ is the highest among all (Figure 5a and 5b). Therefore, $\mathbf{A} \mathbf{I m N D} \mathbf{N D}_{\mathbf{3}}$ is probably a better electron-transporting material than Almm $\mathbf{N D}_{\mathbf{3}}$ because of its high electron mobility. In addition, $\mathbf{A l m N D}_{3}$ seems to be the only material that is ambipolar because of its very similar hole and electron mobility determined by TOF technique. On the other hand, AlmmND may be a better nondopant deep blue emitter because of its low hole mobility, which limits the amount of hole carrier on $\mathbf{A l m m N D}_{\mathbf{3}}$ and enhances the charge balance in normally holedominated devices, one crucial factor for high efficiency OLEDs. As shown in the following sections (2.7 and 2.8), our OLED results are consistent with the forgoing derivation from the TOF data of $\mathbf{A l m N D}_{\mathbf{3}}$ and $\mathbf{A l m m N D}_{\mathbf{3}}$.

2.4. Thermal Properties. Figure 6 shows the differential scanning calorimetry (DSC) thermograms of $\mathbf{A l q}_{\mathbf{3}}, \mathbf{A l N D}_{\mathbf{3}}$, $\mathrm{AlmND}_{3}, \mathrm{GamND}_{3}, \mathrm{AlmmND}_{3}$, and $\mathrm{GammND}_{3}$. In DSC measurements, these metal chelates were first taken from the sample that was purified by a sublimation process. With such prethermal-annealed samples (sublimed-scarped samples), we found that DSC thermograms often show nothing but weak endothermic step transitions, indicative of the glass phase transition temperature $\left(T_{\mathrm{g}}\right)$. To reveal DSC signals of other phase transition temperatures, such as crystallization temperature $\left(T_{\mathrm{c}}\right)$, melting temperature $\left(T_{\mathrm{m}}\right)$, or polymorphic phase transition temperature $\left(T_{\mathrm{p}}\right)$, the sublimed-scarped samples of metal chelates were redissolved in dichloromethane and then evaporated until dryness under reduced pressure at room temperature. In Figure 6 , each metal chelate is displayed with two types of DSC traces. First the heating scan, positioned as the top scan, has a heating temperature beyond the large endothermic signal, $T_{\mathrm{m}}$. The other scans marked with the sequence number of heating scans or cooling scans in Figure 6 are DSC traces with a measuring temperature less than $T_{\mathrm{m}}$, except for AlmpND $\mathbf{3}, \mathbf{G a m p N D} \mathbf{N}_{\mathbf{3}}$, and InmpND $_{3}$ (see Figure S1 for their DSC traces). Two types of heating thermograms were displayed because these metal chelates often exhibit thermal decomposition right after their melting transition, which was evident from observations from a polarized optical microscope (POM). With samples prepared under such conditions, $\mathbf{A l q} \mathbf{q}_{3}$ shows $T_{\mathrm{g}}$ (on-set $T_{\mathrm{g}}$ ) at $174^{\circ} \mathrm{C}$, a broad and small endortherm peaking at $\sim 355^{\circ} \mathrm{C}$ (assigned as $T_{\mathrm{p}}$ ) immediately followed by an exotherm peaked at $367{ }^{\circ} \mathrm{C}$ $\left(T_{c}\right)$, and finally a large endothermic signal at $412{ }^{\circ} \mathrm{C}\left(T_{\mathrm{m}}\right)$. Whereas a $T_{\mathrm{g}}$ of $174{ }^{\circ} \mathrm{C}$ and $T_{\mathrm{m}}$ of $412{ }^{\circ} \mathrm{C}$ are rather consistent with literature data for $\mathbf{A l q}_{3},{ }^{3 \mathrm{c}, 4,6 \mathrm{f}, 17}$ the coupled endortherm and

(17) Higginson, K. A.; Zhang, X.-M.; Papadimitrakopoulos, F. Chem. Mater. 1998, 10, 1017. 

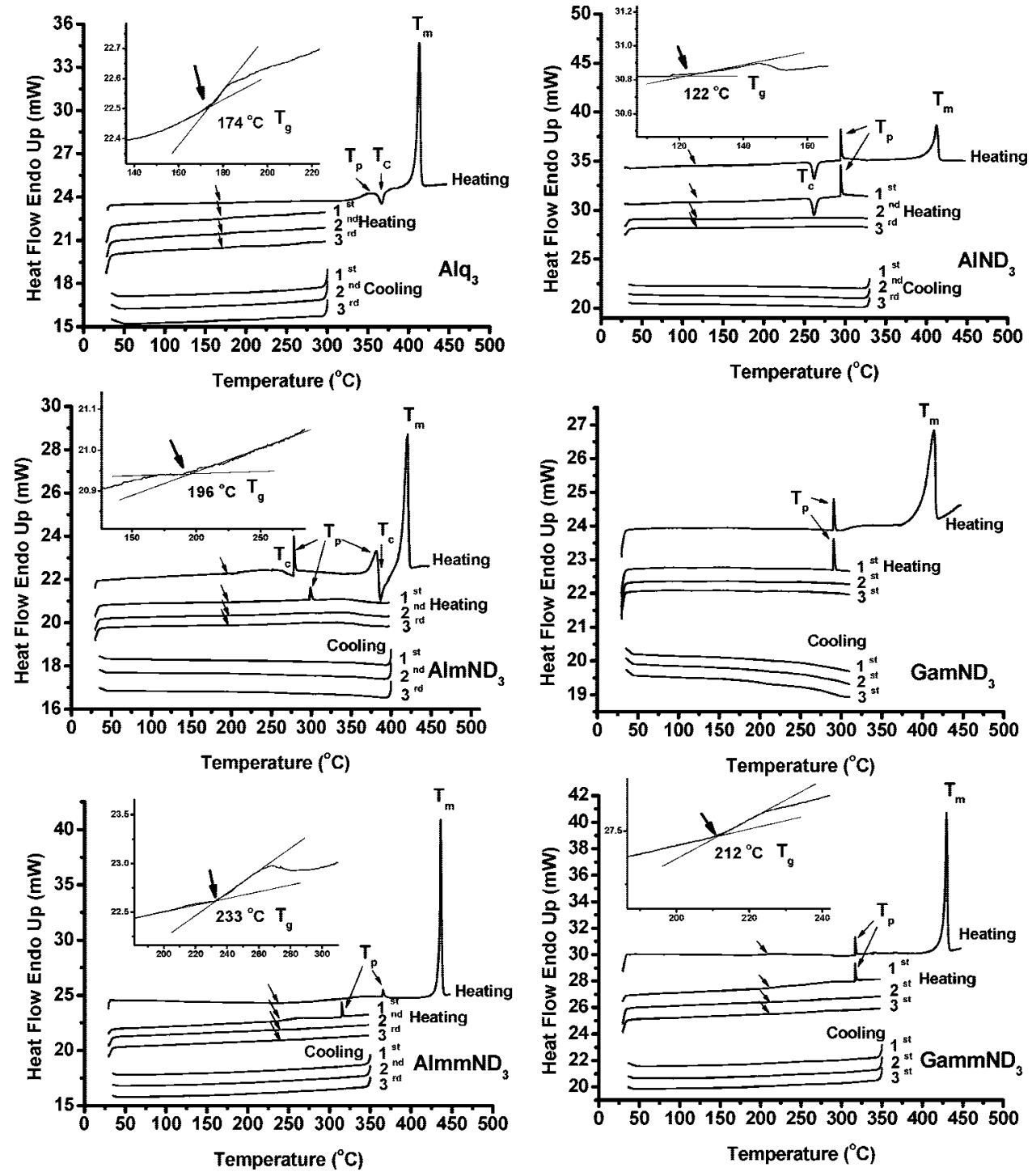

Figure 6. DSC thermograms of $\mathbf{A l q}_{3}, \mathbf{A l N D}_{3}, \mathbf{A l m N D}_{3}, \mathbf{G a m N D}_{3}, \mathbf{A l m m N D}_{3}$, and $\mathbf{G a m m N D}_{3}$.

exotherm have been shown before, although they were reported at higher temperatures of 393 and $396{ }^{\circ} \mathrm{C}$, respectively. ${ }^{4,66,18}$ It is interesting to know that $\mathbf{A l q}_{3}$ will be vaporized (sublimed) when heated around melting temperatures at atmospheric pressure. ${ }^{6 f}$ We have a similar observation (under POM) for $\mathbf{A l q}_{3}$ and most metal chelates reported herein as well. Such an observation is indirect evidence that these new metal chelates preserve their superior volatility as well as $\mathbf{A l q}_{3}$. Unlike those structurally modified $\mathbf{A} \mathbf{A q}_{3}$ blue derivatives, volatile hydroxynaphthyridine metal chelates reported herein have no problem in the fabrication of OLED by thermal-vacuum-deposition processes.

$\mathbf{A l q}_{3}$ has been well-known for its polymorphic and racemic nature and its multiple phase transitions that have been studied

(18) (a) Sano, K.; Kawata, Y.; Urano, T. I.; Mori, Y. J. Mater.Chem. 1992, 2, 767. (b) Braun, M.; Gmeiner, J.; Tzolov, M.; Cölle, M.; Meyer, F. D.; Milius, W.; Hillebrecht, H.; Wendland, O.; von Schütz, J. U.; Brütting, W. J. Chem. Phys. 2001, 114, 9625. (c) Cölle, M.; Gmeiner, J.; Milius, W.; Hillebrecht, Bï; utting, W. Adv. Funct. Mater 2003, 13, 108. (d) Muccini, M.; Loi, M. A.; Kenevey, K.; Zamboni, R.; Masciocchi, N.; Sironi, A. Adv. Mater. 2004, 16, 861. (e) Levichkova, M. M.; Assa, J. J.; Frob, H.; Leo, K. Appl. Phys. Lett. 2006, 88, 201912. in great detail recently., ${ }^{4,6 f, 18}$ It has been suggested that the exotherm observed for $\mathbf{A l q}_{\mathbf{3}}$ in DSC traces is due to crystallization, indicative of the instability of the glassy phase of $\mathbf{A l q}_{\mathbf{3}}$. Some new hydroxynaphthyridine metal chelates, such as Alm$\mathbf{m N D}_{\mathbf{3}}, \mathrm{GamND}_{\mathbf{3}}, \mathrm{GammND}_{\mathbf{3}}, \mathbf{I n m N D}_{\mathbf{3}}$, and InmmND , show no discernible exotherm in DSC traces, a good sign of the morphological stability of their glassy phase. Except for $\mathbf{A I N D}_{\mathbf{3}}$ $\left(T_{\mathrm{g}} \sim 122{ }^{\circ} \mathrm{C}\right.$ ) and $\mathbf{G a m N D}_{3}$ (no detectable $T_{\mathrm{g}}$ in DSC traces), all metal chetates reported herein show $T_{\mathrm{g}}$ values around $183-233{ }^{\circ} \mathrm{C}$, which is higher than $174{ }^{\circ} \mathrm{C}$ for $\mathbf{A l q}_{3}$ (Table 1). Higher $T_{\mathrm{g}}$ 's of metal chetates often imply a higher morphorlogical stability or a glass phase stability, which is beneficial to the operation lifetime of the multiple-thin-film OLEDs. Furthermore, for all aluminum chelates but $\mathbf{A l m p N D}_{\mathbf{3}}$, higher melting temperatures than $\mathbf{A} \mathbf{I q}_{\mathbf{3}}$ were observed by DSC (Table 1). This is a plus because the melting transition of these aluminum chelates was rapidly followed by the thermal decomposition. A higher melting temperature means a higher thermal stability in the case of the aluminum chelates studied herein.

Metal chelates based on mpND are different from the rest. Among all metal chelates, $\mathbf{A l m p N D}_{\mathbf{3}}, \mathbf{G a m p N D}_{\mathbf{3}}$, and $\mathbf{I n m p N D} \mathbf{N D}_{\mathbf{3}}$ 


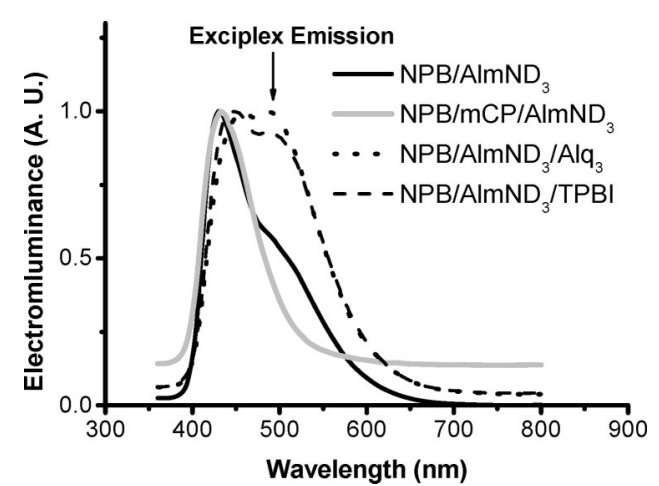

Figure 7. EL spectra of four $\mathrm{NPB} / \mathrm{AlmND}_{3}$-containing OLEDs: ITO/ multiple organic layers/LiF/Al.

were found with relatively low $T_{\mathrm{g}}$ 's of $185-204{ }^{\circ} \mathrm{C}$, and they are easily recognizable in repeated heating scans in DSC measurements (Figure S1). Their $T_{\mathrm{g}}$ 's were always observed prior to a cold crystallization peak without discernible polymorphic phase transition signals (as $T_{\mathrm{p}}$ marked for $\mathbf{A} \mathbf{A N D}_{\mathbf{3}}$, $\mathrm{AlmND}_{3}$, and $\mathrm{AlmmND}_{3}$ in Figure 6). AlmpND $3 \mathbf{G a m p N D}_{\mathbf{3}}$, and $\mathbf{I n m p N D}_{3}$ are also a few exceptions that they do not decompose following the melting transition. Such a difference in thermal properties of $\mathbf{m p N D}$-based metal chelates can be all attributed to the protruded phenyl substituent on a symmetric and nearly globular structure of naphthyridinolate metal chelates.

2.5. Elimination of Adverse Exciplex Formation in NonDoped Blue OLEDs. Deep blue fluorescence of $\mathbf{A l m N D}_{3}$ or $\mathrm{AlmmND}_{3}$ is very attractive for highly demanding blue OLEDs. A simple nondoped bilayer EL device ITO/NPB $(30 \mathrm{~nm}) /$ $\operatorname{AlmND}_{3}(30 \mathrm{~nm}) / \mathrm{LiF}(5 \mathrm{~nm}) / \mathrm{Al}(150 \mathrm{~nm})$ was first fabricated by sequential thermal-vacuum-deposition of NPB, $\mathbf{A l m N D}_{\mathbf{3}}$, $\mathrm{LiF}$, and $\mathrm{Al}$ onto ITO (indium tin oxide)-coated glass substrate. Unfortunately, in addition to the emission band peaking around 430-450 nm of $\mathbf{A l m N D}_{\mathbf{3}}$, a pronounced emission band around $480-540 \mathrm{~nm}$ appears in the EL spectrum of the device (Figure 7).

Such a long wavelength EL devastates the EL efficiency and also impairs the blue color purity of OLEDs. A similar observation was also found for AlmmND $\mathbf{A}_{\mathbf{3}}$ OLEDs. To clarify the origin of the long wavelength EL, three more control devices were then fabricated: ITO/NPB $(30 \mathrm{~nm}) / m \mathrm{CP}(30 \mathrm{~nm}) /$ $\operatorname{AlmND}_{3}(30 \mathrm{~nm}) / \operatorname{LiF}(5 \mathrm{~nm}) / \operatorname{Al}(150 \mathrm{~nm}), \operatorname{ITO} / \mathrm{NPB}(30 \mathrm{~nm}) /$ $\operatorname{AlmND}_{3}(30 \mathrm{~nm}) / \mathbf{A l q}_{\mathbf{3}}(30 \mathrm{~nm}) / \mathrm{LiF}(5 \mathrm{~nm}) / \mathrm{Al}(150 \mathrm{~nm})$, and ITO/ $\mathrm{NPB}(30 \mathrm{~nm}) / \mathrm{AlmND}_{\mathbf{3}}(30 \mathrm{~nm}) / \mathrm{TPBI}(30 \mathrm{~nm}) / \mathrm{LiF}(5 \mathrm{~nm}) / \mathrm{Al}$ $(150 \mathrm{~nm})$. From their EL spectra (Figure 7), we can firmly conclude that the EL around $480-540 \mathrm{~nm}$ is due to the exciplex emission occurring at the interface of NPB and $\mathbf{A l m N D}_{3}$. It is rather common that electron-deficient materials (such as $\mathbf{A l q}_{\mathbf{3}}$ and 1,3,4-oxadiazole compounds) have a propensity to form exciplex with electron-rich hole-transporting materials (such as NPB triarylamine species). ${ }^{19}$ By lowering the HOMO energy level of the hole-transporting material (i.e., reducing the HOMO energy level difference between the hole-transporting material and $\left.\mathbf{A l m N D}_{3}\right),{ }^{19 \mathrm{~d}}$ the problem of the exciplex associated with $\mathrm{AlmND}_{\mathbf{3}}$ can be largely alleviated. As shown in Figure 7, having

(19) (a) Itano, K.; Ogawa, H.; Shirota, Y. Appl. Phys. Lett. 1998, 72, 636. (b) Chan, L.-H.; Lee, R.-H.; Hsieh, C.-F.; Yeh, H.-C.; Chen, C.-T. J. Am. Chem. Soc. 2002, 124, 6469. (c) Guan, M.; Bian, Z. Q.; Zhou, Y. F.; Li, F. Y.; Li, Z. J.; Huang, C. H. Chem. Commun. 2003, 2708. (d) Matsumoto, N.; Nishiyama, M.; Adachi, C. J. Phys. Chem. C 2008, 112,7735 .
Table 2. Electroluminescence Characteristics of Nondoped AlmND $_{3}$ OLEDs Containing CBP with Different Layer Thickness ${ }^{a}$

\begin{tabular}{cccccc}
\hline $\begin{array}{c}\text { CBP } \\
\text { thickness } \\
{[\mathrm{nm}]}\end{array}$ & $\begin{array}{c}\text { max. luminance, } \\
\text { voltage } \\
{\left[\mathrm{cd} / \mathrm{m}^{2}, \mathrm{~V}\right]}\end{array}$ & $\begin{array}{c}\text { luminance, } \\
\text { efficiency, } \\
\text { voltage } \\
{\left[\mathrm{cd} / \mathrm{m}^{2}, \%, \mathrm{~V}\right]}\end{array}$ & $\begin{array}{c}\text { max. } \\
\text { efficiency } \\
{[\%, \mathrm{~cd} / \mathrm{A}, \mathrm{Im} / \mathrm{W}]}\end{array}$ & $\begin{array}{c}\lambda_{\max }{ }^{\mathrm{e}} \mathrm{l} \\
{[\mathrm{nm}]}\end{array}$ & $\begin{array}{c}\mathrm{ClE} 1931 \\
\text { chromaticity } \\
{[x, y]}\end{array}$ \\
\hline 3 & 5555,15 & $119,0.39,5.68$ & $0.53,0.79,0.33$ & 456 & $0.18,0.20$ \\
5 & 4971,15 & $162,0.86,5.63$ & $1.08,1.01,0.45$ & 450 & $0.15,0.11$ \\
10 & 5070,15 & $277,1.63,8.37$ & $1.79,1.51,0.53$ & 448 & $0.15,0.10$ \\
15 & 5606,15 & $315,1.63,9.55$ & $1.74,1.68,0.53$ & 452 & $0.16,0.12$
\end{tabular}

${ }^{a}$ Devices have the configuration of ITO/NPB(40 nm)/CBP $(x \mathrm{~nm}) /$ $\mathbf{A l m N D}_{\mathbf{3}}(30 \mathrm{~nm}) / \mathbf{A l q}_{\mathbf{3}}(20 \mathrm{~nm}) / \mathrm{LiF}(0.5 \mathrm{~nm}) / \mathrm{Al}(150 \mathrm{~nm}), x=3,5,10$, and 15 , respectively. ${ }^{b}$ At current density of $20 \mathrm{~mA} / \mathrm{cm}^{2}$.

a low HOMO energy level around $6.1 \mathrm{eV},{ }^{20}$ arylamine $m \mathrm{CP}$ (1,3-di(9H-carbazol-9-yl)benzene) is effective in preventing the exciplex emission as evident in device ITO/NPB(30 nm)/ $\mathrm{mCP}(30 \mathrm{~nm}) / \mathrm{AlmND}_{3}(30 \mathrm{~nm}) / \mathrm{LiF}(5 \mathrm{~nm}) / \mathrm{Al}(150 \mathrm{~nm})$, although such a device is very poor in EL efficiency and brightness. Also having a low HOMO energy level around $6.3 \mathrm{eV},{ }^{21}$ another hole-transporting material CBP (4,4'-di( $9 H$-carbazol-9-yl)biphenyl) was thus inserted between NPB and $\mathbf{A l m N D}_{3}$. By the variation of CBP layer thickness, we have successfully eliminated the exciplex emission and optimize the performance of the blue devices ITO/NPB $(40 \mathrm{~nm}) / \mathrm{CBP}(x \mathrm{~nm}) / \mathbf{A l m N D}_{\mathbf{3}}(30 \mathrm{~nm}) /$ $\operatorname{Alq}_{3}(20 \mathrm{~nm}) / \mathrm{LiF}(5 \mathrm{~nm}) / \mathrm{Al}(150 \mathrm{~nm})$ optimized with $x=10$ (Table 2). From such CBP-inserted nondoped $\mathrm{AlmND}_{\mathbf{3}}$ OLEDs, we have successfully achieved deep blue ELs $\left(\mathrm{CIE}_{x, y}=0.15\right.$, $0.10)$ with a reasonably good external quantum efficiency $\left(\eta_{\text {ext }}\right)$ reaching $1.79 \%$ (or $1.63 \%$ at $20 \mathrm{~mA} / \mathrm{cm}^{2}$ ) and a maximum brightness of $5070 \mathrm{~cd} / \mathrm{m}^{2}$ (or $277 \mathrm{~cd} \mathrm{~m}^{-2}$ at $20 \mathrm{~mA} / \mathrm{cm}^{2}$ ) (Figure 8). To the best of our knowledge, we believe that a similar exciplex problem of $\mathbf{A l m N D}_{\mathbf{3}}$ has been found for $\mathbf{A I N D}_{\mathbf{3}}$ before and the problem has not been solved until this study. ${ }^{22}$

2.6. As Electron-Transporting Material in Non-Doped $\mathbf{A l m N D}_{3}$ OLEDs. Similar to green emitter $\mathbf{A l q}_{3}$, deep blue emitter $\mathrm{AlmND}_{\mathbf{3}}$ potentially can be used as an electrontransporting material in OLEDs. To gauge such viability, four nondoped $\mathrm{AlmND}_{3}$ OLEDs containing four different ETL materials were fabricated: ITO/NPB(40 nm)/CBP10 nm)/ $\operatorname{AlmND}_{\mathbf{3}}(30 \mathrm{~nm}) / \operatorname{ETL}(20 \mathrm{~nm}) / \mathrm{LiF}(5 \mathrm{~nm}) / \operatorname{Al}(150 \mathrm{~nm})$, where the ETL material is TPBI $\left(2,2^{\prime}, 2^{\prime \prime}\right.$-(1,3,5-phenylene)tris(1-phenyl$1 \mathrm{H}$-benzimidazole), $\mathrm{Bebq}_{2}$ (beryllium bis(benzoquinolin-10olate), $\mathbf{A l q}_{\mathbf{3}}$, or $\mathbf{A} \mathbf{I m N D _ { 3 }}$. As data have shown in Table 3 and Figure 9, in terms of $\eta_{\text {ext }}$, nondoped AlmND $\mathbf{A L}_{3}$ OLEDs are most efficient when $\mathbf{A l m N D}_{3}$ is employed as the ETL material in OLEDs, although it is not as bright as others. However, in terms of power efficiency $\left(\eta_{\mathrm{P}}\right)$, nondoped $\mathbf{A l m N D}_{\mathbf{3}}$ OLEDs having TPBI or $\mathbf{B e b q}_{2}$ are more efficient than ones using $\mathbf{A l q}_{3}$ or $\mathbf{A l m N D}_{3}$ as the ETL materials (Table 3). We notice that $\mathrm{AlmND}_{\mathbf{3}}$ provide OLEDs a relatively low current density and a relatively high turn-on voltage (Figure 9), which are comparable with those of $\mathbf{A l q}_{\mathbf{3}}$ but inferor to those of TPBI or $\mathrm{Bebq}_{2}$. Nevertheless, such results validate the usage of $\mathbf{A l m N D}_{\mathbf{3}}$ as an ETL material in OLEDs.

2.7. $\mathrm{AlND}_{3}, \mathrm{AlmND}_{3}, \mathrm{AlmmND}_{3}$, and $\mathrm{AlmpND}_{3}$ for High Efficiency Non-Doped Deep Blue OLEDs. Having solved the problem of exciplex EL and demonstrated the electron-

(20) Wu, M.-F.; Yeh, S.-J.; Chen, C.-T.; Murayama, H.; Tsuboi, T.; Li, W.-S.; Chao, I.; Liu, S.-W.; Wang, J.-K. Adv. Funct. Mater 2007, 17, 1887.

(21) Hill, I. G.; Rajagopai, A.; Kahn, A. J. Appl. Phys. 1998, 84, 3236.

(22) Chen, Chin Hsin, Department of Photonics and Display Institute, National Chiao Tung University, private communication. 

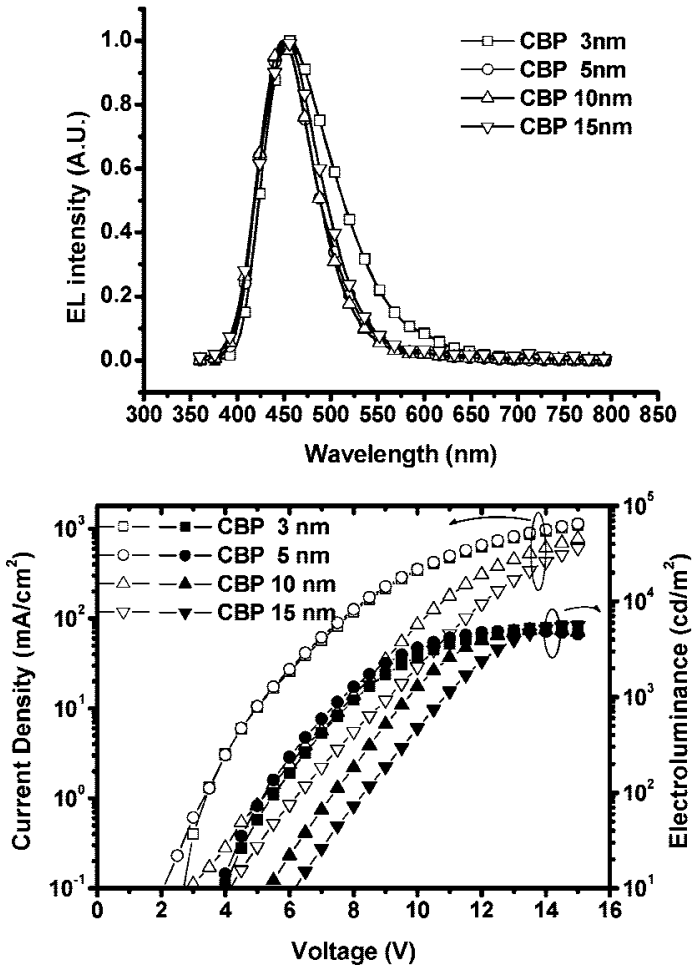
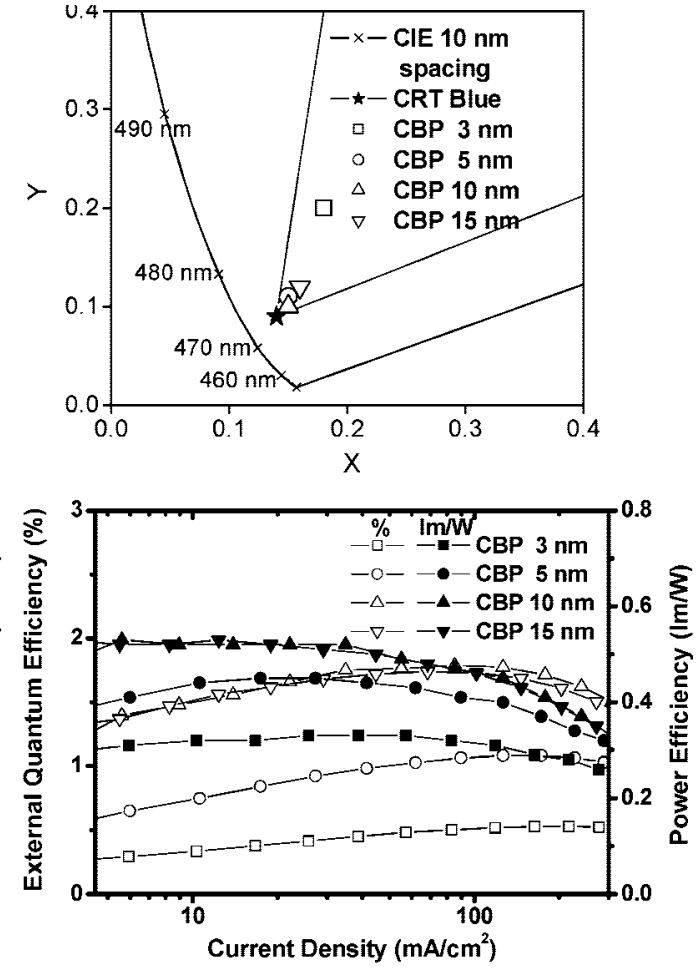

Figure 8. EL characteristics of $\mathrm{ITO} / \mathrm{NPB}(40 \mathrm{~nm}) / \mathrm{CBP}(x \mathrm{~nm}) / \mathbf{A l m N D}_{\mathbf{3}}(30 \mathrm{~nm}) / \mathbf{A l q}_{3}(20 \mathrm{~nm}) / \mathrm{LiF}(0.5 \mathrm{~nm}) / \mathrm{Al}(150 \mathrm{~nm}), x=3,5$, 10, and 15 , respectively.

Table 3. Electroluminescence Characteristics of Nondoped $\mathrm{AlmND}_{3}$ OLEDs with Various ETL Materials ${ }^{a}$

\begin{tabular}{lccccc}
\hline ETL & $\begin{array}{c}\text { max. } \\
\text { luminance } \\
\text { and voltage } \\
{\left[\mathrm{cd} / \mathrm{m}^{2}, \mathrm{~V}\right]}\end{array}$ & $\begin{array}{c}\text { luminance, } \\
\text { efficiency, } \\
\text { voltage } \\
{\left[\mathrm{cd} / \mathrm{m}^{2}, \%, \mathrm{~V}\right]^{b}}\end{array}$ & $\begin{array}{c}\text { max. } \\
\text { efficiency } \\
{[\%, \mathrm{~cd} / \mathrm{A}, \mathrm{Im} / \mathrm{W}]}\end{array}$ & $\begin{array}{c}\lambda_{\max } \mathrm{el} \\
{[\mathrm{nm}]}\end{array}$ & $\begin{array}{c}\text { CIE 1931 } \\
\text { chromaticity } \\
{[x, y]}\end{array}$ \\
\hline TPBI & 6000,15 & $240,1.15,6.2$ & $1.86,1.79,0.86$ & 454 & $0.16,0.13$ \\
$\mathrm{Bebq}_{2}$ & 7140,15 & $340,1.67,5.6$ & $1.81,1.84,0.98$ & 458 & $0.15,0.13$ \\
$\mathbf{A l q}_{3}$ & 5070,15 & $277,1.63,8.4$ & $1.79,1.51,0.53$ & 448 & $0.15,0.10$ \\
$\mathbf{A l m N D}_{3}$ & 5240,15 & $310,1.85,6.8$ & $1.96,1.65,0.84$ & 452 & $0.15,0.10$
\end{tabular}

${ }^{a} \mathrm{ITO} / \mathrm{NPB}(40 \mathrm{~nm}) / \mathrm{CBP}(10 \mathrm{~nm}) / \mathbf{A l m N D}_{\mathbf{3}}(30 \mathrm{~nm}) / \mathrm{ETL}(20 \mathrm{~nm}) / \mathrm{LiF}(5$ $\mathrm{nm}) / \mathrm{Al}(150 \mathrm{~nm}) .{ }^{b}$ At $20 \mathrm{~mA} / \mathrm{cm}^{2}$.

transporting property of $\mathbf{A l m N D}_{3}$, we are ready to examine and find the best aluminum chelates of ND, mND, mmND, and mpND for nondoped deep blue OLEDs. Having $\mathbf{A l m N D}_{\mathbf{3}}$ as the electron-transporting layer, four nondoped OLEDs were based on $\mathbf{A l N D}_{3}, \mathbf{A l m N D}_{3}, \mathbf{A l m m N D}_{3}$, and AlmpND $\mathbf{A l}_{3}$ ITO/ $\mathrm{NPB}(40 \mathrm{~nm}) / \mathrm{CBP}(10 \mathrm{~nm}) / \mathrm{Blue} \mathrm{Al}$ chelates $(30 \mathrm{~nm}) / \mathbf{A l m N D}_{\mathbf{3}}(20$ $\mathrm{nm}) / \mathrm{LiF}(0.5 \mathrm{~nm}) / \mathrm{Al}(150 \mathrm{~nm})$ were fabricated and characterized (Table 4 and Figure 10).

As it can be anticipated from their solution or solid-state fluorescence wavelength, the $\mathbf{A l m N D}_{3}$ OLED showed a much deeper blue EL with 1931 Commision Internationale de L'Eclairage $x, y$ coordinates $\left(\mathrm{CIE}_{x, y}=0.15,0.09\right)$ than that of AIND $_{3}$ OLED $\left(\mathrm{CIE}_{x, y}=0.15,0.19\right)$. However, we do not anticipate that $\mathbf{A l m N D}_{\mathbf{3}}$ OLED performs better than does $\mathbf{A I N D}_{\mathbf{3}}$ OLED considering its fluorescence quantum yield. Since fluorescence quantum yields of $\mathbf{A I N D}_{\mathbf{3}}$ are higher than those of $\mathbf{A l m N D}_{3}$ either in solution or in the solid state, we attribute such a result to the charge balancing in the OLED, which has a great influence on the efficiency of the charge-recombination in the OLED. More surprisingly, the AlmmND $\mathbf{A l}_{3}$ OLED shows the shortest EL wavelength $\left(\lambda_{\max }\right.$ EL $\left.\sim 436 \mathrm{~nm}\right)$, the highest $\eta_{\text {ext }}$ of $4.18 \%$ (or $4.11 \%$ at $20 \mathrm{~mA} / \mathrm{cm}^{2}$ ), and the brightest EL of $445 \mathrm{~cd} / \mathrm{m}^{2}$ at $20 \mathrm{~mA} / \mathrm{cm}^{2}$. Considering the structural difference among $\mathbf{A I N D}_{\mathbf{3}}, \mathbf{A} \mathbf{I m N D} \mathbf{N D}_{\mathbf{3}}$, and $\mathbf{A} \mathbf{m m} \mathbf{N D}_{3}$, it is hard to conceive that an insignificant methyl substituent or the number of methyl substituents can exert that much on $\eta_{\text {ext }}$ and EL brightness. Plausibly, among four aluminum chelates, we may recognize $\mathbf{A l m m N D}_{3}$ as an exceptional one based on the red-shifted fluorescence from solution to the solid state. The red-shifting fluorescence is $443 \rightarrow 447 \mathrm{~nm}, 415 \rightarrow 431 \mathrm{~nm}, 416 \rightarrow 419 \mathrm{~nm}$, and $417 \rightarrow 425 \mathrm{~nm}$ for $\mathbf{A l N D}_{\mathbf{3}}, \mathbf{A l m N D} \mathbf{N}_{\mathbf{3}}, \mathbf{A} \mathbf{m m} \mathbf{N D}_{\mathbf{3}}$, and $\mathbf{A l m p N D} \mathbf{N}_{\mathbf{3}}$, respectively. Energywise, this corresponds to a red-shifting energy of $723,895,172$, and $451 \mathrm{~cm}^{-1}$, respectively for four aluminum chelates. $\mathbf{A l m m N D}_{\mathbf{3}}$ has the smallest red-shifted fluorescence among all. Accordingly, we surmise that, in the solid state, Almm $\mathbf{N D}_{3}$ aggregates in a quite different fashion from the other aluminum chelates. Compared with other aluminum chelates, such aggregation enables high efficiency of charge recombination (or charge balance) and thus the $\eta_{\text {ext }}$ (or $\eta_{\mathrm{P}}$ ) of $\mathbf{A l m m N D}_{\mathbf{3}}$ OLEDs. For AlmmND $\mathbf{A l}_{\mathbf{3}}$, the low hole mobility (lower than its electron mobility) helps in balancing the charge of AlmmND $\mathbf{A L E D s}_{\mathbf{3}}$ OLE

We have also examined the performance of blue OLEDs with $\mathbf{G a m N D}_{3}, \mathbf{G a m m N D}_{3}, \mathbf{I n m N D}_{3}$, or InmmND $\mathbf{I n}_{3}$ as the nondoped light-emitting layer (Table S1). As it can be anticipated from the fact that a heavy atom will quench the fluorescence, indium chelates performed the worst in terms of EL efficiency or brightness. However, this is not exactly the case for gallium chelates. Comparing data in Table 4 and Table S1, the

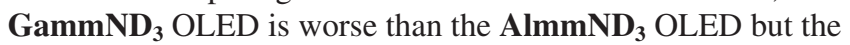
$\mathbf{G a m N D}_{3}$ OLED is better than the AlmND $\mathbf{A L L E D}_{\mathbf{3}}$ OLEvertheless, once again, we verified the same trend of OLED performance; namely, $\mathbf{m m N D}$ is better than $\mathbf{m N D}$ for gallium or indium metal chelates as nondoped deep blue light-emitting materials for OLEDs.

2.8. Nondoped AlmmND $\mathrm{ALEDs}_{3}$ with Various Metal Chelates as Electron-Transporting Layer. Knowing all group III metal chelates are potential ETL material in OLEDs, we fabricated a series of $\mathbf{A} \mathbf{I m m N D} \mathbf{N}_{\mathbf{3}}$-based nondoped blue OLEDs 

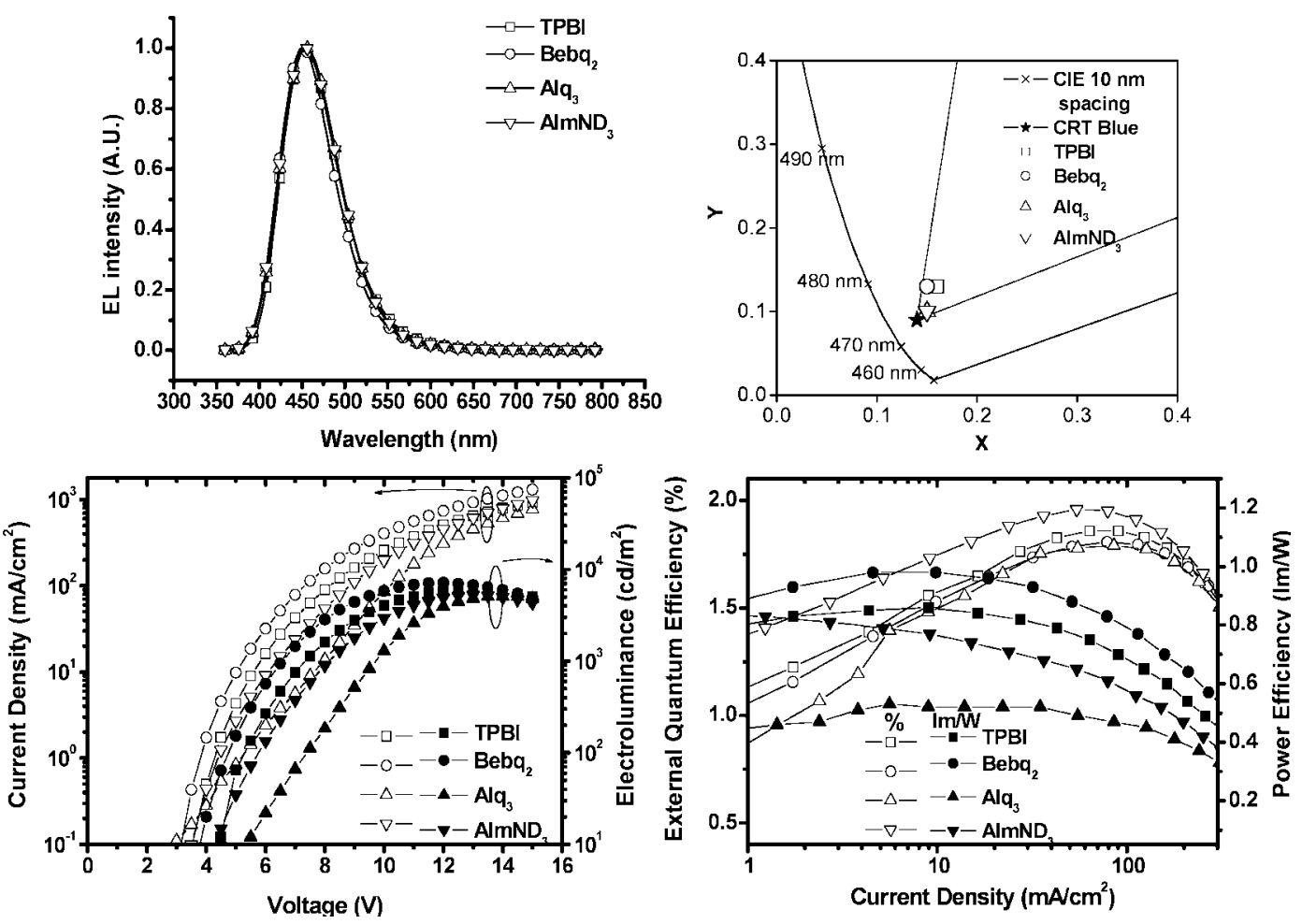

Figure 9. EL characteristics of $\mathrm{ITO} / \mathrm{NPB}(40 \mathrm{~nm}) / \mathrm{CBP}(10 \mathrm{~nm}) / \mathrm{AlmND}_{\mathbf{3}}(30 \mathrm{~nm}) / \mathrm{ETL}(20 \mathrm{~nm}) / \mathrm{LiF}(0.5 \mathrm{~nm}) / \mathrm{Al}(150 \mathrm{~nm})$, where $\mathrm{ETL}$ is TPBI, Bebq ${ }_{2}, \mathrm{Alq}_{\mathbf{3}}$, and $\mathbf{A l m N D}_{3}$, respectively.

Table 4. Electroluminescence Characteristics of Nondoped OLEDs of AIND 3, AlmND $_{3}$, AlmmND $_{3}$, and AlmpND 3 blue Al chelates ${ }^{a}$

\begin{tabular}{lccccc}
\hline $\begin{array}{c}\text { Al } \\
\text { chelates }\end{array}$ & $\begin{array}{c}\text { max. luminance } \\
\text { and voltage } \\
{\left[\mathrm{cd} / \mathrm{m}^{2}, \mathrm{~V}\right]}\end{array}$ & $\begin{array}{c}\text { luminance, } \\
\text { efficiency, voltage } \\
{\left[\mathrm{cd} / \mathrm{m}^{2}, \%, \mathrm{~V}\right]}\end{array}$ & $\begin{array}{c}\text { max. efficiency } \\
{[\%, \mathrm{~cd} / \mathrm{A}, \mathrm{Im} / \mathrm{W}]}\end{array}$ & $\begin{array}{c}\lambda_{\text {max }}{ }^{\mathrm{el}} \\
{[\mathrm{nm}]}\end{array}$ & $\begin{array}{c}\mathrm{ClE} 1931 \\
\text { chromaticity } \\
{[x, y]}\end{array}$ \\
\hline $\mathbf{A l N D}_{3}$ & 2286,15 & $216,0.75,8.31$ & $0.76,1.09,0.45$ & 466 & $0.15,0.19$ \\
$\mathbf{A l m N D}_{3}$ & 3824,15 & $279,1.86,7.57$ & $1.91,1.43,0.77$ & 448 & $0.15,0.09$ \\
$\mathbf{A l m m N D}_{3}$ & 3792,15 & $445,4.11,9.36$ & $4.18,2.27,0.86$ & 436 & $0.15,0.07$ \\
AlmpND $_{3}$ & 4078,15 & $306,1.58,9.63$ & $1.62,1.58,0.71$ & 452 & $0.15,0.12$
\end{tabular}

${ }^{a}$ Devices have the configuration of ITO/NPB(40 nm)/CBP(10 nm)/ Blue Al chelates $(30 \mathrm{~nm}) / \mathrm{AlmND}_{\mathbf{3}}(20 \mathrm{~nm}) / \mathrm{LiF}(0.5 \mathrm{~nm}) / \mathrm{Al}(150 \mathrm{~nm}) .{ }^{b}$ At current density of $20 \mathrm{~mA} / \mathrm{cm}^{2}$.

with a variation of ETL material, $\mathbf{A l N D}_{\mathbf{3}}, \mathbf{A l m N D}_{\mathbf{3}}, \mathbf{A l m m N D}_{\mathbf{3}}$,

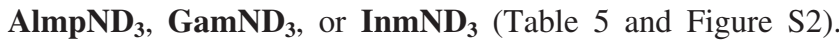
Here, for a fair comparison, the $\mathbf{A l m m N D}_{\mathbf{3}}$ OLED having $\mathrm{AlmND}_{3}$ as ETL material is a refabricated one, not the same one in Table 4 and Figure 10. As the data show in Table 5, all devices exhibit virtually the same $\lambda_{\max }{ }^{\text {el }} 432 \mathrm{~nm}$ and a very similar deep blue color chromaticity $\mathrm{CIE}_{x, y}=0.15-0.16$, $0.07-0.08$, consistent with all OLEDs having the same deep blue nondoped emitter AlmmND . Regardless of ETL materials, all deep blue OLEDs have a relatively high EL efficiency with $\eta_{\text {ext }}$ being more than $3.0 \%$. In terms of EL efficiency, the $\mathbf{A l m m N D}_{\mathbf{3}}$ OLED having $\mathbf{A l m N D}_{\mathbf{3}}$ as the ETL material is the most outstanding. This OLED has $\eta_{\text {ext }}$ reaching $3.77 \%$ and $\eta_{\mathrm{P}}$ over $0.80 \mathrm{~lm} / \mathrm{W}$ at a current density of $20 \mathrm{~mA} / \mathrm{cm}^{2}$. From OLED results in section 2.7 and 2.8, it is very clear that $\mathbf{A l m m N D}_{3}$ is the most efficient nondoped deep blue emitter but $\mathbf{A l m N D}_{\mathbf{3}}$ is the best ETL material for it.

2.9. AlmND ${ }_{3}$ as the Host Material for Blue Perylene and Deep Blue 9,10-Diphenylanthracene Dopants. To demonstrate the wide band gap nature of hydroxynaphthyridine metal chelates, we have fabricated a series of $\mathbf{A l m N D}_{3}$ OLEDs containing perylene or 9,10-diphenylanthracene (DPA) as highly efficient blue or deep blue dopant materials. Perylene is a highly fluorescent blue emitter with $\lambda_{\max }{ }^{\text {fl }} 467 \mathrm{~nm}$ (in clyclohexane) and $\Phi_{\mathrm{f}} 94 \%{ }^{23}$ However, in the solid state blue perylene becomes a poor fluorophore, a yellow one, due to the severe molecular aggregation that brings about concentration quenching, and a diminished and red-shifting fluorescence takes place. The fluorescence of DPA is even bluer and stronger showing $\lambda_{\max }{ }^{\mathrm{fl}} 438 \mathrm{~nm}$ (in cyclohexane) and $\Phi_{f} 100 \%{ }^{23}$ Similar to blue perylene, deep blue DPA has the inherent problem of crystallizing when deposited as a thin film that prohibits its nondopant usage in a device. ${ }^{24}$ Whereas some reports are available for the dopant usage of perylene, ${ }^{25}$ there is no known literature case of the dopant usage of DPA in OLEDs to date. This can be simply attributed to the lack of appropriate host material, a wide band gap one, required for such a deep blue DPA dopant.

We took $0.5,2$, and 4 wt \% dopant concentration of both perylene and DPA in the fabrication of dopant-based $\mathbf{A l m N D}_{3}$ OLEDs. The EL characteristics of both series of devices are displayed in Figures 11 and 12, and their data are summarized in Table 6.

(23) Berlman, I. B. Handbook of Fluorescence Spectra of Aromatic Molecules, 2nd ed.; Academic Press: New York, 1971; pp 264 and 399.

(24) Adachi, C.; Tsutsui, T.; Sato, S. Appl. Phys. Lett. 1990, 56, 799.

(25) (a) Kojima, H.; Ozawa, A.; Takahshi, T.; Nagaoka, M.; Homma, T.; Nagatomo, T.; Omoto, O. J. Electrochem. Soc. 1997, 144, 3628. (b) Mi, B. X.; Gao, Z. Q.; Lee, C. S.; Lee, C. T.; Kwong, H. L.; Wong, N. B. App. Phys. Lett. 1999, 75, 4055. (c) Lu, P.; Hong, H.; Cai, G.; Djurovich, P.; Weber, W. P.; Thompson, M. E. J. Am. Chem. Soc. 2000, 122, 7480. (d) Jiang, X.-Y.; Zhang, Z.-L.; Zheng, Z.-Y.; Wu, Y.-Z.; Xu, S.-H. Thin Solid Films 2001, 401, 251. (e) Wu, C.-C.; Lin, Y.-T.; Chiang, H.-H.; Cho, T.-Y.; Chen, C.-W.; Wong, K.-T.; Liao, Y.-L.; Lee, G.-H.; Peng, S.-M. Appl. Phys. Lett. 2002, 81, 577. (f) Ni, S. Y.; Wang, X. R.; Wu, Y. Z.; Chen, H. Y.; Zhu, W. Q.; Jiang, X. Y.; Zhang, Z. L.; Sun, R. G. Appl. Phys. Lett. 2004, 85, 878. (g) Jarikov, V. V. J. Appl. Phys. 2006, 100, 014901. (h) Tse, S.-C.; Tsung, K.-K.; So, S.-K. Appl. Phys. Lett. 2007, 90, 213502. (i) Lee, R.-H.; Hung, Y.-W.; Wang, Y.-Y.; Chang, H.-Y. Thin Solid Films 2008, 516, 5062 . 

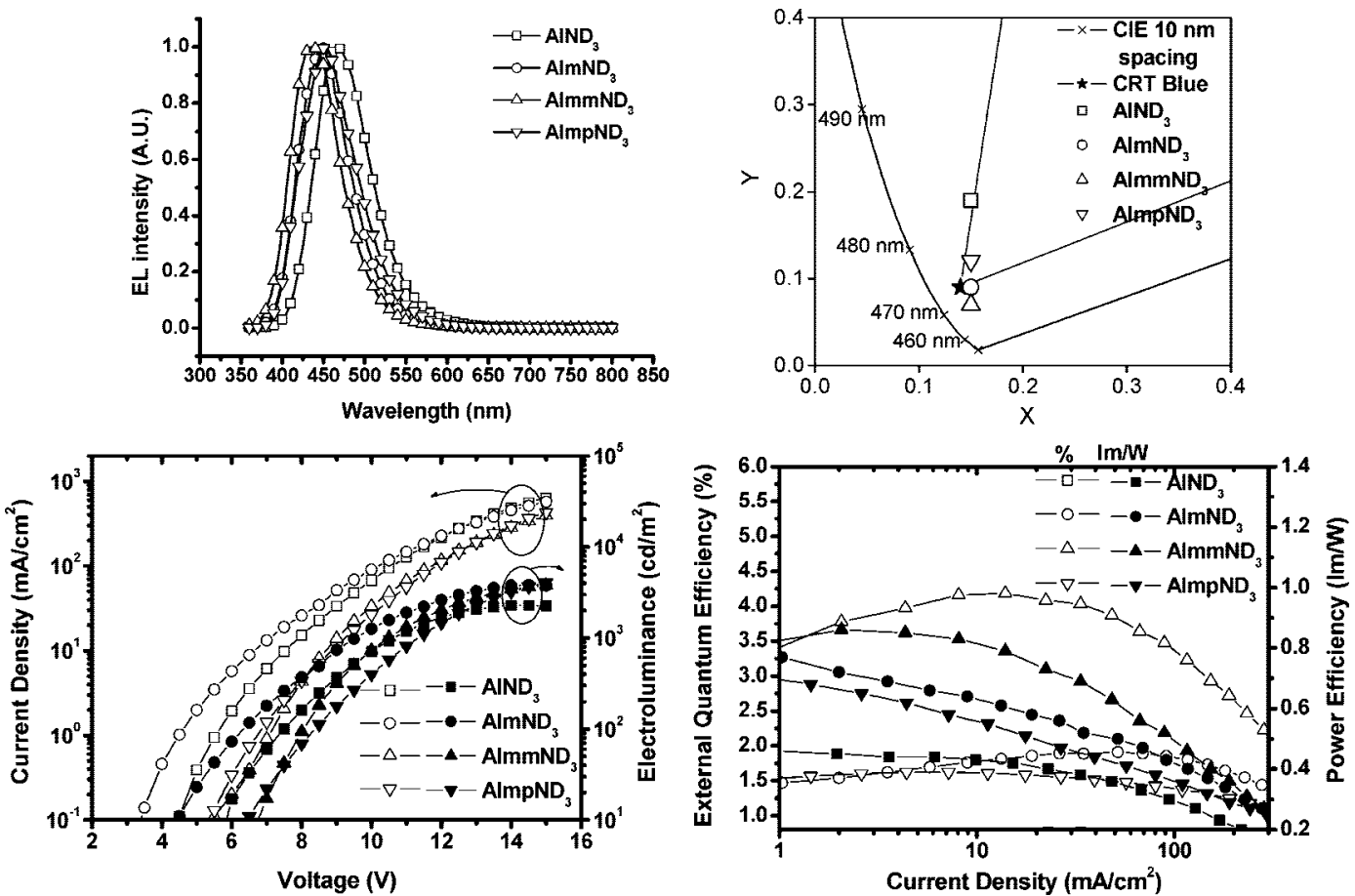

Figure 10. EL characteristics of $\mathrm{ITO} / \mathrm{NPB}(40 \mathrm{~nm}) / \mathrm{CBP}(10 \mathrm{~nm}) / \mathrm{Blue} \mathrm{Al}$ chelate $(30 \mathrm{~nm}) / \mathrm{ETL}(20 \mathrm{~nm}) / \mathrm{LiF}(0.5 \mathrm{~nm}) / \mathrm{Al}(150 \mathrm{~nm})$, where $\mathrm{Blue} \mathrm{Al} \mathrm{chelate}$ is $\mathrm{AlND}_{3}, \mathrm{AlmND}_{3}, \mathrm{AlmmND}_{3}$, and AlmpND 3 , respectively.

Table 5. Electroluminescence Characteristics of Nondoped OLEDs of AlmmND ${ }_{3}$ with Various Metal Chelates as ETL Materials ${ }^{a}$

\begin{tabular}{|c|c|c|c|c|c|}
\hline ETL & $\begin{array}{l}\text { max. luminance } \\
\text { and voltage } \\
{\left[\mathrm{cd} / \mathrm{m}^{2}, \mathrm{~V}\right]}\end{array}$ & $\begin{array}{c}\text { luminance, } \\
\text { efficiency, voltage } \\
{\left[\mathrm{cd} / \mathrm{m}^{2}, \%, \mathrm{~V}\right]^{b}}\end{array}$ & $\begin{array}{l}\max \text {. efficiency } \\
{[\%, \mathrm{~cd} / \mathrm{A}, \mathrm{Im} / \mathrm{W}]}\end{array}$ & $\begin{array}{l}\lambda_{\max }{ }^{e l} \\
{[\mathrm{~nm}]}\end{array}$ & $\begin{array}{c}\text { CIE } 1931 \\
\text { chromaticity } \\
{[x, y]}\end{array}$ \\
\hline $\mathrm{AIND}_{3}$ & 3313,15 & $369,3.40,8.92$ & $3.67,2.00,1.04$ & 432 & $0.15,0.07$ \\
\hline $\mathrm{AlmND}_{3}$ & 4444,15 & $401,3.77,7.75$ & $3.79,2.00,0.94$ & 432 & $0.15,0.07$ \\
\hline $\mathrm{AlmmND}_{3}$ & 4879,15 & $329,3.01,8.60$ & $3.27,1.78,0.84$ & 432 & $0.16,0.07$ \\
\hline $\mathrm{AlmpND}_{3}$ & 5487,15 & $376,3.23,8.24$ & $3.41,1.99,1.13$ & 432 & $0.16,0.08$ \\
\hline $\mathrm{GamND}_{3}$ & 4694,15 & $416,3.67,8.18$ & $3.68,2.09,0.93$ & 432 & $0.15,0.07$ \\
\hline $\mathrm{InmND}_{3}$ & 3848,15 & $376,3.62,8.62$ & $3.67,1.91,0.91$ & 432 & $0.15,0.07$ \\
\hline
\end{tabular}

${ }^{a}$ Devices have the configuration of ITO/NPB(40 nm)/CBP(10 nm)/ $\operatorname{AlmmND}_{3}(30 \mathrm{~nm}) / \operatorname{ETL}(20 \mathrm{~nm}) / \mathrm{LiF}(0.5 \mathrm{~nm}) / \mathrm{Al}(150 \mathrm{~nm}) .{ }^{b}$ At current density of $20 \mathrm{~mA} / \mathrm{cm}^{2}$.

Dopant concentration $0.5 \mathrm{wt} \%$ was found to be optimum for either perylene or DPA. The vibronic emission observed at the low energy side of the major EL band is the distinct feature of a not so blue preylene EL, indicating a sufficient Förster energy transfer between the $\mathbf{A l m N D}_{\mathbf{3}}$ host and perylene dopant. Compared to the undoped device (second entry of Table 4), the maximum EL efficiency of the perylene-doped device was enhanced more than four times to $\sim 3.06 \mathrm{~lm} / \mathrm{W}$, or more than three times to $\sim 4.67 \mathrm{~cd} / \mathrm{A}$. At a current density of $20 \mathrm{~mA} / \mathrm{cm}^{2}, \eta_{\text {ext }}$ was $3.13 \%$, which was enhanced 1.7 times compared to an undoped device. The maximum electroluminance also increased to $12420 \mathrm{~cd} / \mathrm{m}^{2}$, a greater than 3-fold enhancement than that of the undoped device, although this is at a price of deep blue color purity. The perylene-doped device had a chromaticity of $\mathrm{CIE}_{x, y}=$ $0.14,0.17$, less deep blue than $\mathrm{CIE}_{x, y}=0.15,0.09$ of the undoped device (second entry of Table 4). Nonetheless, the performance of the $0.5 \mathrm{wt} \%$ perylene-doped $\mathbf{A l m N D}_{3}$ OLED reported herein is one of the best perylene dopant devices known in literature. ${ }^{25}$ Similar enhancement of the OLED performance was also observed for DPA-doped devices, although the enhancement was to a smaller extent when compared with that of perylene-doped OLEDs. However, the deep blue color purity was elevated to a higher level, $\mathrm{CIE}_{x, y}$ $=0.15,0.06$. After the comparison with emission spectra of solution DPA, solid state $\mathbf{A l m N D}_{3}$, and solid state DPA (fluorescence spectra shown in Figure 12), the EL spectra of the DPA-doped AlmND $\mathbf{A L}_{\mathbf{3}}$ OLED can be recognized as a coemission from both DPA and $\mathbf{A l m N D}_{3}$. Since the main emission wavelength of DPA is shorter than that for $\mathbf{A} \mathbf{I m} \mathbf{N D}_{\mathbf{3}}$, the coemission EL observed for the DPA-doped AlmND $\mathbf{A D}_{\mathbf{3}}$ OLED gave rise to the deepest blue color (see inserted 1931 CIE chromaticity diagram in Figure 12). Considering the inadequate overlapping of the absorption spectrum of DAP and the emission spectrum of $\mathbf{A} \mathbf{I m N D} \mathbf{N D}_{\mathbf{3}}$ (not shown in Figure 12), we can conceive that Förster energy transfer between

(26) (a) Xie, Z. Y.; Huang, J. S.; Li, C. N.; Liu, S. Y.; Wang, Y.; Li, Y. Q.; Shen, J. C. Appl. Phys. Lett. 1999, 74, 641. (b) Steuber, F.; Staudigel, J.; Strössel, M.; Simmerer, J.; Winnacker, A.; Spreitzer, H.; Weissörtel, F.; Salbeck, J. Adv. Mater. 2000, 12, 130. (c) Xie, Z. Y.; Feng, J.; Huang, J. S.; Liu, S. Y.; Wang, Y.; Shen, J. C. Synth. Met. 2000, 108, 81. (d) Zhang, Z.; Jiang, X.; Xu, S. Thin Solid Films 2000, 363, 61. (e) Liu, S.; Hunag, J.; Xie, Z.; Wang, Y.; Chen, B. Thin Solid Films 2000, 363, 294. (f) Chuen, C. H.; Tao, Y. T. Appl. Phys. Lett. 2002, 81, 4499. (g) Li, G.; Shinar, J. Appl. Phys. Lett. 2003, 83, 5359. (h) Cheng, G.; Zhao, Y.; Zhang, Y.; Liu, S.; He, F.; Zhang, H.; Ma, Y. Appl. Phys. Lett. 2004, 84, 4457. (i) Liu, T.-H.; Wu, Y.-S.; Lee, M.T.; Chen, H.-H.; Liao, C.-H.; Chen, C. H. Appl. Phys. Lett. 2004, 85, 4304. (j) Cheng, G.; Xie, Z.; Zhao, Y.; Zhang, Y.; Xia, H.; Ma, Y.; Liu, S. Thin Solid Films 2005, 484, 54. (k) Xie, W.; Meng, M.; Li, C.; Zhao, Y.; Liu, S. Opt. Quant. Electron. 2005, 37, 943. (1) Li, M.; Li, W.; Niu, J.; Chu, B.; Li, B.; Sun, X.; Zhang, Z.; Hu, Z. SolidState Electron. 2005, 49, 1956. (m) Tao, S.; Peng, Z.; Zhang, X.; Wu, S. J. Lumin. 2006, 121, 568. (n) Zhang, G. H.; Hua, Y. L.; Petty, M. C.; Wu, K. W.; Zhu, F. J.; Niu, X.; Hui, J. L.; Liu, S.; Wu, X. M.; Yin, S. G.; Deng, J. C. Displays 2006, 27, 187. (o) Choukri, H.; Fischer, A.; Forget, S.; Chénais, S.; Castex, M.-C.; Adés, D.; Slove, A.; Geffroy, B. Appl. Phys. Lett. 2006, 89, 183513. (p) Hsiao, C.-H.; Lin, C.-F.; Lee, J.-H. J. Appl. Phys. 2007, 102, 094508. (q) Huang, H.-H.; Chu, S.-Y.; Kao, P.-C.; Chen, Y.-C. Thin Solid Films 2008, 516, 5669. (r) Tang, S.; Liu, M.; Lu, P.; Cheng, G.; Zeng, M.; Xie, Z.; Xu, H.; Wang, H.; Yang, B.; Ma, Y.; Yan, D. Org. Electron. 2008, 9, 241. (s) Duan, Y.; Mazzeo, M.; Maiorano, V.; Mariano, F.; Qin, D.; Cingolani, R.; Gigli, G. Appl. Phys. Lett. 2008, 92, 113304. 

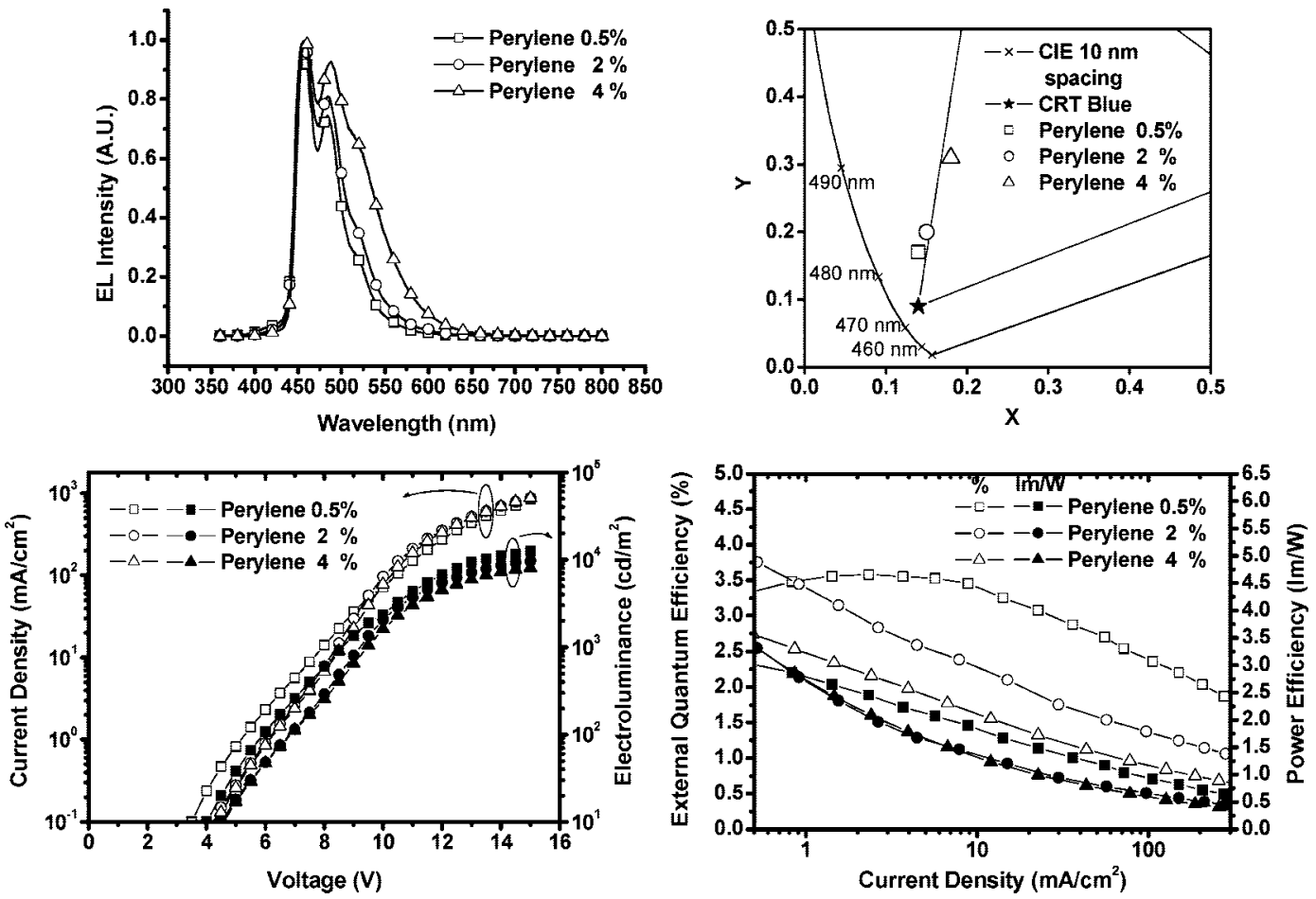

Figure 11. EL characteristics of $\mathrm{ITO} / \mathrm{NPB}(40 \mathrm{~nm}) / \mathrm{CBP}(10 \mathrm{~nm}) / \mathrm{AlmND}_{3}:$ perylene $(x \%, 30 \mathrm{~nm}) / \mathrm{AlmND}_{\mathbf{3}}(20 \mathrm{~nm}) / \mathrm{LiF}(0.5 \mathrm{~nm}) / \mathrm{Al}(150 \mathrm{~nm})$, where $x$ is 0.5 , 2 , or 4 , the weight percent of perylene dopant.
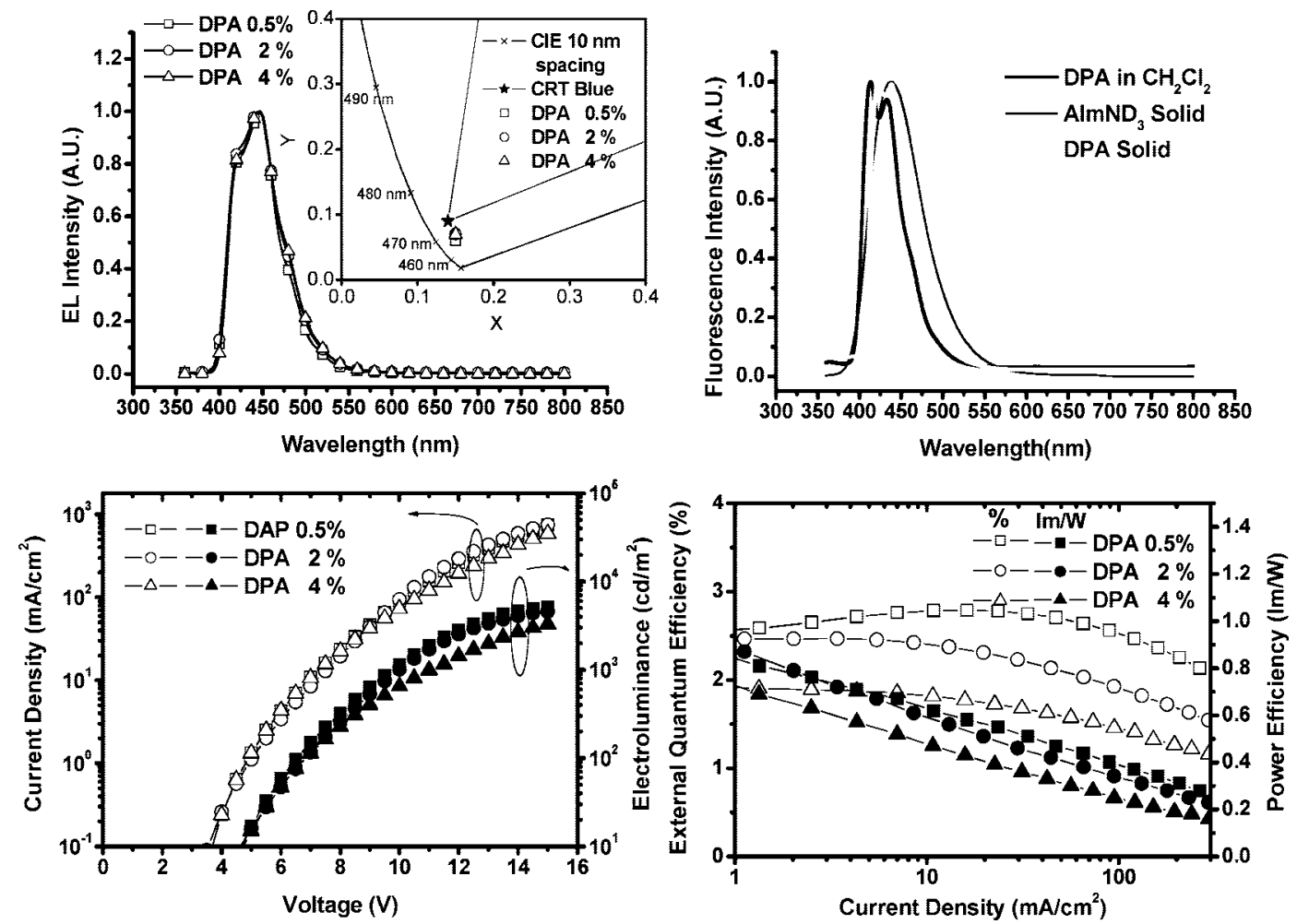

Figure 12. EL characteristics of $\mathrm{ITO} / \mathrm{NPB}(40 \mathrm{~nm}) / \mathrm{CBP}(10 \mathrm{~nm}) / \mathrm{AlmND}_{3}: \mathrm{DPA}(x \%, 30 \mathrm{~nm}) / \mathrm{AlmND}_{\mathbf{3}}(20 \mathrm{~nm}) / \mathrm{LiF}(0.5 \mathrm{~nm}) / \mathrm{Al}(150 \mathrm{~nm}), \mathrm{where} x$ is $0.5,2$, or 4 , the weight percent of DPA dopant

the $\mathbf{A l m N D}_{3}$ host and DPA dopant is somewhat incomplete, even though the HOMO energy level of the $\mathbf{A l m N D}_{\mathbf{3}}$ host is low enough for the DPA dopant (but the LUMO energy level of $\mathbf{A} \mathbf{I m N D} \mathbf{N}_{3}$ is not high enough for the DPA dopant). Despite such a coemission, to the best of our knowledge, this is the first observation of a deep blue EL from DPA.
2.10. $\operatorname{AlmND}_{3}$ as the Host Material for High Efficiency White OLEDs with Rubrene Yellow Dopant. Yellow fluorophore rubrene is probably the most commonly used dopant accompanying blue fluorescent host material in the fabrication of white OLEDs. ${ }^{26,27}$ Fluorescence spectrum of $\mathbf{A l m N D}_{\mathbf{3}}$ is partially overlapping with the absorption spectrum of rubrene 
Table 6. Electroluminescence Characteristics of $\mathrm{AlmND}_{3}$ OLEDs with Various Dopant (Perylene or 9,10-Diphenylanthracene) Concentrations $^{a}$

\begin{tabular}{lccccc}
\hline $\begin{array}{c}\text { dopant } \\
\text { concn } \\
\text { [wt \%] }\end{array}$ & $\begin{array}{c}\text { max. luminance } \\
\text { and voltage } \\
{\left[\mathrm{cd} / \mathrm{m}^{2}, \mathrm{~V}\right]}\end{array}$ & $\begin{array}{c}\text { luminance, } \\
\text { efficiency, } \\
\text { voltage } \\
{\left[\mathrm{cd} / \mathrm{m}^{2}, \%, \mathrm{~V}\right]^{b}}\end{array}$ & $\begin{array}{c}\max . \\
\text { efficiency } \\
{[\%, \mathrm{~cd} / \mathrm{A}, \mathrm{Im} / \mathrm{W}]}\end{array}$ & $\begin{array}{c}\lambda_{\max }^{\mathrm{el}} \\
{[\mathrm{nm}]}\end{array}$ & $\begin{array}{c}\text { CIE 1931 } \\
\text { chromaticity } \\
{[x, y]}\end{array}$ \\
\hline \multicolumn{7}{c}{ Perylene as Dopant } \\
0.5 & 12420,15 & $810,3.13,8.3$ & $3.56,4.67,3.06$ & 456 & $0.14,0.17$ \\
4 & 9610,15 & $590,1.98,8.7$ & $3.77,3.51,3.28$ & 456 & $0.15,0.20$ \\
4 & 8060,15 & $580,1.38,8.9$ & $2.73,5.45,3.69$ & 458 & $0.18,0.31$ \\
0.5 & 5120,15 & $278,2.78,5.8$ & $2.80,1.39,0.89$ & 448 & $0.15,0.06$ \\
2 & 4595,15 & $259,2.31,5.4$ & $2.47,1.38,0.87$ & 446 & $0.15,0.07$ \\
4 & 3295,15 & $203,1.75,5.6$ & $1.90,1.91,0.69$ & 446 & $0.18,0.07$
\end{tabular}

${ }^{a}$ ITO/NPB(40 nm)/CBP(10 nm)/AlmND 3 :Dopant $(x \%, 30 \mathrm{~nm}) /$ $\operatorname{AlmND}_{3}(20 \mathrm{~nm}) / \operatorname{LiF}(5 \mathrm{~nm}) / \operatorname{Al}(150 \mathrm{~nm})$, where $x=0.5$, 2 , and 4 (weight percent) for perylene or 9,10-diphenylanthracene (DPA) dopant. ${ }^{b}$ At $20 \mathrm{~mA} / \mathrm{cm}^{2}$

(Figure S3 left), and white fluorescence is feasible with an appropriate ratio of mixed $\mathbf{A l m N D}_{\mathbf{3}}$ and rubrene (Figure S3 right).

We have demonstrated that the deep blue $\mathbf{A l m N D}_{\mathbf{3}}$ is a good host material for rubrene in generating high EL efficiency white OLEDs. A series of OLEDs ITO/NPB(40 nm $) / \mathrm{CBP}(10 \mathrm{~nm}) /$ $\operatorname{AlmND}_{3}: \operatorname{rubrene}(x \%, 30 \mathrm{~nm}) / \mathbf{A l m N D}_{\mathbf{3}}(20 \mathrm{~nm}) / \mathrm{LiF}(0.5 \mathrm{~nm}) /$ $\mathrm{Al}(150 \mathrm{~nm})$ with a variation of rubrene dopant concentration 0.5-4 wt\% and EL characteristics of such AlmND $\mathbf{N D}_{\mathbf{3}}$ :rubrene OLEDs are shown in Figure 13 and their data are summarized in Table 7.

Similar to most rubrene-based white OLEDs, an authentic white color purity $\left(\mathrm{CIE}_{x, y}=0.32,0.38\right)$ was achieved at a very low dopant concentration, 0.5 wt $\%$ of $\mathbf{A l m N D}_{3}$ (first entry of Table 7). Any higher dopant concentration simply impairs the white color purity of OLEDs. For such white OLEDs at a brightness of $100 \mathrm{~cd} / \mathrm{m}^{2}, \eta_{\text {ext }}$ is $4.25 \%$, which is equivalent to an $\eta_{\mathrm{P}}$ of $8.67 \mathrm{~lm} / \mathrm{W}$, one of the highest among literature-known rubrene-based white OLEDs. ${ }^{26,27}$ The color rendering index (CRI) of such white (two-color-component) OLEDs was determined to be in the range $45-50$, and it is in general inferior to CRI $\sim 80$ of three-color-component white OLEDs. ${ }^{28}$ At

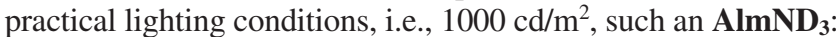
rubrene white OLED has an $\eta_{\text {ext }}$ of $\sim 3.9 \%$ or $\eta_{\mathrm{P}}$ of $5.1 \mathrm{~lm} / \mathrm{W}$ (Figure 13). With few exceptions, ${ }^{27}$ this EL efficiency at 1000 $\mathrm{cd} / \mathrm{m}^{2}$ also outperforms most literature-known rubrene-based two-element white OLEDs. Also, a doped device with a $4 \%$ rubrene concentration is virtually a yellow OLED, $\mathrm{CIE}_{x, y}=$ $0.45,0.51$ (Figure 13 and the fourth entry of Table 7). Its high efficiency, $4.56 \%, 15.83 \mathrm{~cd} / \mathrm{A}$, or $11.94 \mathrm{~lm} / \mathrm{W}$, at $100 \mathrm{~cd} / \mathrm{m}^{2}$ and high brightness $\left(1930 \mathrm{~cd} / \mathrm{m}^{2}\right.$ at $\left.20 \mathrm{~mA} / \mathrm{cm}^{2}\right)$ outperforms most currently known yellow OLEDs. ${ }^{29}$ The high EL efficiency of such rubrene-based white or yellow OLEDs can be attributed to the high electron mobility of $\mathbf{A} \mathbf{m} \mathbf{m} \mathbf{N D}_{\mathbf{3}}$. High electron mobility is rarely observed for the host material in the white or yellow

(27) (a) Huang, J.; Li, G.; Wu, E.; Xu, Q.; Yang, Y. Adv. Mater. 2006, 18, 114. (b) Huang, J.; Hou, W.-J.; Li, J.-H.; Li, G.; Yang, Y. Appl. Phys. Lett. 2006, 89, 133509. (c) Tsai, Y.-C.; Jou, J.-H. Appl. Phys. Lett. 2006, $89,243521$.

(28) (a) D'Andrade, B. W.; Forrest, S. R. Adv. Mater. 2004, 16, 1585. (b) Misra, A.; Kumar, P.; Kamalasanan, Chandra, S. Semicomd. Sci. Technol. 2006, 21, R35. (c) Yeh, S.-J.; Chen, H.-Y.; Wu, M.-F.; Chan, L.-H.; Chiang, C.-L.; Yeh, H.-C.; Chen, Lee, J.-H. Org. Electron. 2006, $7,137$.

(29) See: Chiang, C.-L.; Tseng, S.-M.; Chen, C.-T.; Hsu, C.-P.; Shu, C.-F. Adv. Funct. Mater 2008, 18, 248, and references therein.
OLEDs, and it facilitates the charge balance and hence the EL efficiency of OLEDs.

\section{Conclusion}

We have reported the first series of group III metal chelates as the authentic deep blue analogues of green $\mathbf{A l q}_{3}$. A large quantity of these deep blue metal chelates are readily available now due to our improved synthesis and facial purification method applicable for them. Unlike several currently known blue analogues of $\mathbf{A l q} \mathbf{q}_{3}$, these deep blue group III metal chelates are volatile and thermally stable enough for OLED fabrication by a vacuum-thermal-deposition process. For OLEDs, we have overcome the problem of exciplex formation, which has hampered $\mathbf{A I N D}$ from practical usage in OLEDs before. High efficiency (maximum $\eta_{\text {ext }}>4.0 \%$ ) and deep blue $\left(\mathrm{CIE}_{x, y}=0.15\right.$, 0.07) nondoped OLEDs were achieved for AlmmND $\mathbf{A l}_{3}$. The wide band gap of these deep blue metal chelates, 6.4 and $3.0 \mathrm{eV}$ for $\mathbf{A l m N D}_{\mathbf{3}}$ HOMO and LUMO energy levels, respectively, enable their usage as the host material for perylene blue dopant or deep blue 9,10-diphenylanthracene. These group III metal chelates,

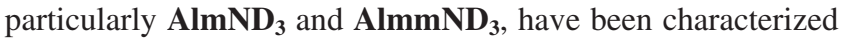
for the charge carrier mobility by a time-of-flight technique. Both $\mathbf{A l m N D}_{\mathbf{3}}$ and $\mathbf{A l m m N D}_{\mathbf{3}}$ exhibit high electron mobility, comparable with or even higher than that of $\mathrm{BeBq}_{2}$ or $\mathbf{A l q}_{3}$. Moreover, $\mathbf{A l m N D}_{3}$ is ambipolar with a similar mobility of $10^{-4}$ $\mathrm{cm}^{2} / \mathrm{Vs}$ for both hole and electron. The success of highly efficient white OLEDs (or yellow OLEDs) based on a rubrene dopant is attributed to the high electron (and hole) mobility of the host material, $\mathbf{A} \mathbf{I m N D} \mathbf{N D}_{\mathbf{3}}$. We have demonstrated the versatile and effective application of hydroxynaphthyridine-based group III metal chelates for OLEDs. More high performance OLEDs can be anticipated now due to the availability of long-thought, wide band gap, deep blue group III metal chelates.

\section{Experimental Section}

General Information. Both solution and solid-state fluorescence quantum yields $\left(\Phi_{f}\right.$ 's) of the blue metal chelates were determined by the integrating-sphere method. ${ }^{30}$ Photoluminescence (PL) spectra were recorded on a Hitachi fluorescence spectrophotometer F-4500, and the same spectrophotometer was used to record the EL spectra of OLEDs. Melting points $\left(T_{\mathrm{m}} \mathrm{s}\right)$, glass transition temperatures $\left(T_{\mathrm{g}}\right.$ ' $\left.\mathrm{s}\right)$, and crystallization temperatures $\left(T_{\mathrm{c}}\right.$ 's) of respective compounds were measured via differential scanning calorimetry (DSC) using a Perkin-Elmer DSC-6 differential scanning calorimeter. The HOMO energy levels of the thin-film samples of metal chelates were studied by ultraviolet photoemission spectroscopy (UPS). The experimental detail of UPS measurement has been described before. ${ }^{31}$ LUMO energy levels were estimated by subtracting the energy gap $(\Delta E)$ from HOMO energy levels. $\Delta E$ was determined by the on-set absorption energy from the absorption spectra of the materials. UV-visible electronic absorption spectra were recorded on a Hewlett-Packard 8453 Diode Array spectrophotometer. The method of time-of-flight (TOF) in measuring charge carrier mobility has been reported before. ${ }^{32}$ Data collection of the X-ray crystallography analysis was carried out on a Brucker X8APEX CCD

(30) (a) de Mello, J. C.; Wittmann, H. F.; Friend, R. H. Adv. Mater. 1997, 9, 230. (b) Chiang, C.-L.; Wu, M.-F.; Dai, D.-C.; Wen, Y.-S.; Wang, J.-K.; Chen, C.-T. Adv. Funct. Mater 2005, 15, 231.

(31) Wu, C.-I.; Lee, G.-R.; Lin, C.-T.; Chen, Y.-H.; Hong, Y.-H.; Liu, W.G.; Wu, C.-C.; Wong, K.-T.; Chao, T.-C. Appl. Phys. Lett. 2005, 87, 242107.

(32) (a) Wu, M.-F.; Yeh, S.-J.; Chen, C.-T.; Murayama, H.; Tsuboi, T.; Li, W.-S.; Chao, I.; Liu, S.-W.; Wang, J.-K. Adv. Funct. Mater. 2007, 17, 1887. (b) Liu, S.-W.; Lee, J.-H.; Lee, C.-C.; Chen, C.-T.; Wang, J.-K. Appl. Phys. Lett. 2007, 91, 142106. 

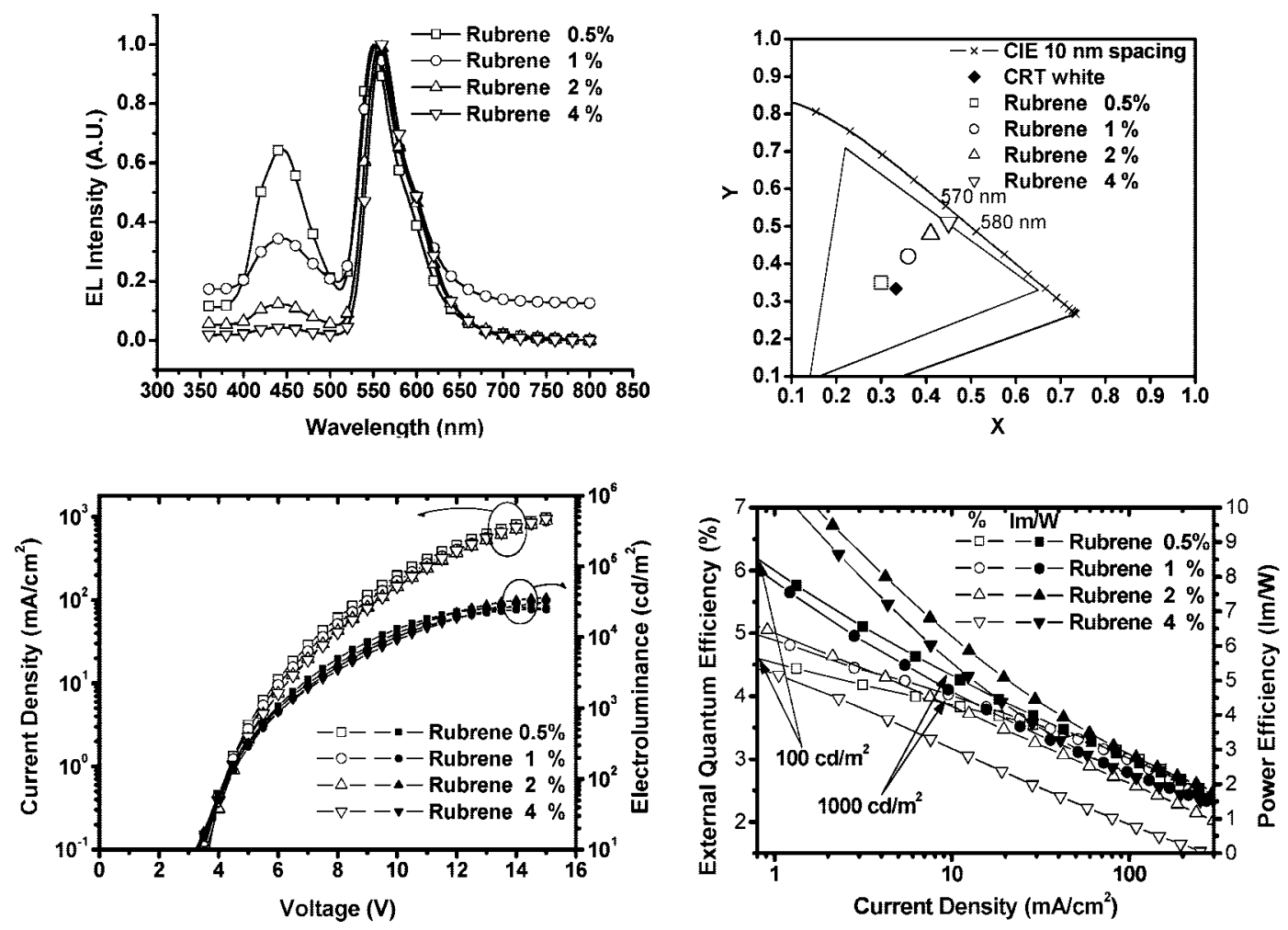

Figure 13. EL characteristics of ITO/NPB $(40 \mathrm{~nm}) / \mathrm{CBP}(10 \mathrm{~nm}) / \mathrm{AlmND}_{\mathbf{3}}:$ rubrene $(x \%, 30 \mathrm{~nm}) / \mathbf{A l m N D}_{\mathbf{3}}(20 \mathrm{~nm}) / \mathrm{LiF}(0.5 \mathrm{~nm}) / \mathrm{Al}(150 \mathrm{~nm})$, where $x$ is 0.5 , 1,2 , or 4 , the weight percent of rubrene dopant. EL efficiency $\left(\eta_{\mathrm{ext}}\right.$ or $\left.\eta_{\mathrm{P}}\right)$ at 100 or $1000 \mathrm{~cd} / \mathrm{m}^{2}$ electroluminance is arrow-marked for the device with 0.5 wt $\%$ rubrene dopant.

Table 7. Electroluminescence Characteristics of White OLEDs with AlmND $_{3}$ Host and Various Dopant (Rubrene) Concentration ${ }^{a}$

\begin{tabular}{|c|c|c|c|c|c|}
\hline $\begin{array}{l}\text { rubrene } \\
\text { concn } \\
\text { [wt \%] }\end{array}$ & $\begin{array}{l}\text { max. luminanceand } \\
\text { voltage } \\
{\left[\mathrm{cd} / \mathrm{m}^{2}, \mathrm{~V}\right]} \\
\end{array}$ & $\begin{array}{c}\text { luminance, } \\
\text { efficiency, voltage } \\
{\left[\mathrm{cd} / \mathrm{m}^{2}, \%, \mathrm{~V}\right]^{\mathrm{b}}} \\
\end{array}$ & $\begin{array}{l}\text { efficiency at } 100 \\
\text { and } 1000 \mathrm{~cd} / \mathrm{m}^{2} \\
{[\%, \mathrm{~cd} / \mathrm{A}, \mathrm{Im} / \mathrm{W}]}\end{array}$ & $\begin{array}{c}\lambda_{\max }{ }^{\mathrm{el}} \\
{[\mathrm{nm}]}\end{array}$ & $\begin{array}{c}\text { CIE } 1931 \\
\text { chromaticity } \\
{[x, y]} \\
\end{array}$ \\
\hline 0.5 & 26710,15 & $1830,3.67,6.58$ & $\begin{array}{l}4.25,11.55,8.67 \\
3.91,9.65,5.13\end{array}$ & 444,550 & $0.30,0.35$ \\
\hline 1 & 24810,15 & $1670,3.73,6.75$ & $\begin{array}{l}4.97,11.17,8.20 \\
3.97,8.93,4.58\end{array}$ & 444,554 & $0.36,0.42$ \\
\hline 2 & 36290,15 & $2260,3.47,7.02$ & $\begin{array}{l}5.35,17.46,13.03 \\
3.98,12.97,6.78\end{array}$ & 444,558 & $0.41,0.48$ \\
\hline
\end{tabular}

${ }^{a}$ Devices have the configuration of ITO/NPB(40 nm)/CBP(10 nm)/AlmND ${ }_{3}$ :rubrene $x \%(30 \mathrm{~nm}) / \mathrm{AlmND}(20 \mathrm{~nm}) / \mathrm{LiF}(0.5 \mathrm{~nm}) / \mathrm{Al}(150 \mathrm{~nm}), x=0.5$, $1,2,4$, respectively. ${ }^{b}$ At current density of $20 \mathrm{~mA} / \mathrm{cm}$.

diffractometer at $100 \mathrm{~K}$ for $\mathbf{A l N D}_{3} \cdot \mathrm{CH}_{2} \mathrm{Cl}_{2}$ single crystals. The experimental detail of $\mathrm{X}$-ray diffraction and their data process in solving the crystal structure can be found elsewhere. ${ }^{30 \mathrm{~b}}$

The fabrication of OLEDs and their EL characterization also have been described before. ${ }^{19 b, 33}$ The device was placed close to the photodiode such that all the forward light entered the photodiode. The effective size of the emitting diodes was $3.14 \mathrm{~mm}^{2}$, which is significantly smaller than the active area of the photodiode dectector, a condition known as "under-fillling", satisfying the measurement protocol. ${ }^{34}$ This is one of the most conventional ways in measuring the EL efficiency of OLEDs, although sometimes experimental errors may arise due to the non-Lambertian emission of OLEDs. ${ }^{35}$ The color rendering index (CRI) of white OLEDs was measured by a spectroradiometer (Specbos 1201, JETI Technishe Instrumente $\mathrm{GmbH})$.

(33) Yeh, S.-J.; Wu, M.-F.; Chen, C.-T.; Song, Y.-H.; Chi, Y.; Ho, M.-H.; Hsu, S.-F.; Chen, C. H. Adv. Mater. 2005, 17, 285.

(34) Forrest, S. R.; Bradley, D. D. C.; Thompson, M. E. Adv. Mater. 2003, 15, 1043.

(35) Tanaka, I.; Tokito, S. Jpn. J. Appl. Phys 2004, 43, 7733.
${ }^{1} \mathrm{H}$ and ${ }^{13} \mathrm{C}$ NMR specra were recorded on a Bruker AMX-400 $\mathrm{MHz}$ or AVA-400 MHz Fourier-transform spectrometer at room temperature. Elemental analyses (on a Perkin-Elmer $2400 \mathrm{CHN}$ Elemental Analyzer) and electron impact (EI), fast atom bombardment (FAB), or matrix-assisted laser desorption/ionization timeof-flight (MALDI-TOF) mass spectra (on a VA Analytical 11-250J or 4800 MALDI TOF/TOF Analyzer) were recorded by the Elemental Analyses and Mass Spectroscopic Laboratory in-house service of the Institute of Chemistry, Academic Sinica.

Materials. For the materials used in device fabrication, $\mathrm{Bebq}_{2}$, DPA (9,10-diphenylanthracene), perylene, and rubrene are commercially available materials and they were used without further purification. NPB (1,4-bis(1-naphthylphenylamino)biphenyl), CBP (4,4'-bis(9-carbazolyl)-2,2'-biphenyl), $m \mathrm{CP}$ (1,3-bis(9-carbazolyl)benzene), TPBI $\left(2,2^{\prime}, 2^{\prime \prime}\right.$-(1,3,5-phenylene)tris[1-phenyl-1H-benzimidazole]), and $\mathbf{A l q} \mathbf{q}_{\mathbf{3}}$ were prepared via published methods and were subjected to gradient sublimation prior to use.

Synthesis of Tris(4-hydroxy-1,5-naphthyridinato)aluminum $\left(\right.$ AlND $\left._{3}\right)$. To a toluene solution $(4.5 \mathrm{~mL})$ was added ND $(0.15 \mathrm{~g}$, $1.0 \mathrm{mmol})$ and aluminum triisopropoxide $(0.07 \mathrm{~g}, 0.34 \mathrm{mmol})$. The 
reaction mixture was heated at reflux under nitrogen for $1 \mathrm{~h}$. During the reaction, a formation of milky white solid emitting blue fluorescence was observed. After cooling, the reaction solution was filtered to isolate a white solid. After washing with $n$-hexanes, the solid was subjected to zone-temperature sublimation. The pure product was isolated as a white solid. Yield: $76 \%(0.12 \mathrm{~g}) .{ }^{1} \mathrm{H}$ NMR $\left(400 \mathrm{MHz}, \mathrm{CD}_{2} \mathrm{Cl}_{2}\right): \delta 8.77(\mathrm{~d}, 1 \mathrm{H}, J=4.75 \mathrm{~Hz}), 8.73-8.67(\mathrm{~m}$, $4 \mathrm{H}), 8.56(\mathrm{~d}, 1 \mathrm{H}, J=8.54 \mathrm{~Hz}), 8.51-8.47(\mathrm{~m}, 2 \mathrm{H}), 7.73(\mathrm{dd}, 1 \mathrm{H}$, $J=8.56 \mathrm{~Hz}, J=4.72 \mathrm{~Hz}), 7.56(\mathrm{dd}, 1 \mathrm{H}, J=8.60 \mathrm{~Hz}, J=4.75$ $\mathrm{Hz}), 7.49(\mathrm{dd}, 1 \mathrm{H}, J=8.50 \mathrm{~Hz}, J=4.74 \mathrm{~Hz}), 7.29(\mathrm{~d}, 1 \mathrm{H}, J=$ $4.59 \mathrm{~Hz}), 6.93(\mathrm{~d}, 1 \mathrm{H}, J=5.33 \mathrm{~Hz}), 6.90(\mathrm{~d}, 1 \mathrm{H}, J=5.34 \mathrm{~Hz})$, $6.81(\mathrm{~d}, 1 \mathrm{H}, J=5.32 \mathrm{~Hz}) .{ }^{13} \mathrm{C}$ NMR $\left(100 \mathrm{MHz}, \mathrm{CDCl}_{3}\right): \delta 165.17$, $164.98,164.65,156.28,155.73,155.70,144.80,144.43,144.17$, $144.07,142.39,141.87,141.45,141.37,138.84,138.18,138.01$, 125.13, 124.55, 109.80, 109.62, 109.08. FAB-MS: calcd 462.10, $m / z=463.1\left(\mathrm{M}+\mathrm{H}^{+}\right)$. Anal. Found (Calcd) for $\mathrm{C}_{24} \mathrm{H}_{15} \mathrm{AlN}_{6} \mathrm{O}_{3}: \mathrm{C}$, 62.31 (62.34); H, 2.93 (3.27); N, 17.88 (18.17).

Synthesis of Tris(4-hydroxy-8-methyl-1,5-naphthyridinato)aluminum $\left(\mathrm{AlmND}_{3}\right)$. This compound was synthesized in the same manner as $\mathbf{A I N D}$, except that $\mathbf{m N D}$ (1.00 g, $6.2 \mathrm{mmol}$ ) was used instead of ND. The pure product was isolated as a white solid. Yield: $86 \%(0.90 \mathrm{~g}) .{ }^{1} \mathrm{H}$ NMR $\left(400 \mathrm{MHz}, \mathrm{CDCl}_{3}\right): \delta 8.73-8.70$ $(\mathrm{m}, 3 \mathrm{H}), 8.57(\mathrm{~d}, 1 \mathrm{H}, J=4.90 \mathrm{~Hz}), 8.52(\mathrm{~d}, 1 \mathrm{H}, J=4.91 \mathrm{~Hz})$, $7.51(\mathrm{~d}, 1 \mathrm{H}, J=4.81 \mathrm{~Hz}), 7.42(\mathrm{~d}, 1 \mathrm{H}, J=4.90 \mathrm{~Hz}), 7.27(\mathrm{~d}, 1 \mathrm{H}$, $J=4.76 \mathrm{~Hz}), 7.11(\mathrm{~d}, 1 \mathrm{H}, J=4.94), 6.94(\mathrm{~d}, 1 \mathrm{H}, J=5.34 \mathrm{~Hz})$, $6.91(\mathrm{~d}, 2 \mathrm{H}, J=5.34 \mathrm{~Hz}), 2.84(\mathrm{~s}, 3 \mathrm{H}), 2.79$ (s, 3H), $2.77(\mathrm{~s}, 3 \mathrm{H})$. ${ }^{13} \mathrm{C}$ NMR $\left(100 \mathrm{MHz}, \mathrm{CDCl}_{3}\right): \delta 165.58,165.44,165.12,154.74$, $154.22,154.20,153.22,152.70,152.56,143.95,143.76,143.70$, $143.65,143.62,141.75,137.99,137.31,137.18,125.25,125.23$, 124.69, 109.68, 109.40, 108.91, 17.76, 17.67. FAB-MS: calcd $504.15, m / z=505.1\left(\mathrm{M}+\mathrm{H}^{+}\right)$. Anal. Found (Calcd) for $\mathrm{C}_{27} \mathrm{H}_{21} \mathrm{AlN}_{6} \mathrm{O}_{3}$ : C, 64.20 (64.28); H, 4.33 (4.20); N, 16.36 (16.66).

Synthesis of Tris(4-hydroxy-2,8-dimethyl-1,5-naphthyridinato)aluminum $\left(\mathbf{A l m m N D} \mathbf{N}_{3}\right)$. This compound was synthesized in the same manner as $\mathbf{A l N D}$, except that $\mathbf{m m N D}(0.50 \mathrm{~g}, 2.9 \mathrm{mmol})$ was used instead of ND. The pure product was isolated as a white solid. Yield: $86 \%(0.45 \mathrm{~g}) .{ }^{1} \mathrm{H}$ NMR $\left(400 \mathrm{MHz}, \mathrm{CDCl}_{3}\right): \delta 8.46$ $(\mathrm{d}, 1 \mathrm{H}, J=4.88 \mathrm{~Hz}), 8.43(\mathrm{~d}, 1 \mathrm{H}, J=4.88 \mathrm{~Hz}), 7.42(\mathrm{~d}, 1 \mathrm{H}, J=$ $4.88 \mathrm{~Hz}), 7.34(\mathrm{~d}, 1 \mathrm{H}, J=4.88 \mathrm{~Hz}), 7.18(\mathrm{~d}, 1 \mathrm{H}, J=4.92 \mathrm{~Hz})$, $7.00(\mathrm{~d}, 1 \mathrm{H}, J=4.96 \mathrm{~Hz}), 6.81(\mathrm{~s}, 2 \mathrm{H}), 6.80(\mathrm{~s}, 1 \mathrm{H}), 2.80(\mathrm{~s}, 3 \mathrm{H})$, $2.76(\mathrm{~s}, 3 \mathrm{H}), 2.74(\mathrm{~s}, 3 \mathrm{H}), 2.61(\mathrm{~s}, 3 \mathrm{H}), 2.60(\mathrm{~s}, 6 \mathrm{H}) .{ }^{13} \mathrm{C} \mathrm{NMR}$ $\left(100 \mathrm{MHz}, \mathrm{CDCl}_{3}\right): \delta$ 165.03, 164.76, 164.24, 163.59, 152.01, $151.57,151.40,143.09,143.05,142.99,142.74,142.48,140.61$, $136.89,136.23,136.09,125.08,124.60,109.67,109.26,108.89$, 26.36, 26.29, 17.60, 17.53. FAB-MS: calcd 546.20, $\mathrm{m} / \mathrm{z}=547.2$ $\left(\mathrm{M}+\mathrm{H}^{+}\right)$. Anal. Found (Calcd) for $\mathrm{C}_{30} \mathrm{H}_{27} \mathrm{AlN}_{6} \mathrm{O}_{3}$ : C, 65.54 (65.93); H, 4.94 (4.98); N, 15.37 (15.38).

Synthesis of Tris(4-hydroxy-8-dimethyl-2-phenyl-1,5-naphthyridinato)aluminum $\left(\mathbf{A l m p N D}_{3}\right)$. This compound was synthesized in the same manner as $\mathbf{A l N D})_{3}$, except that mpND $(0.20 \mathrm{~g}$, $0.9 \mathrm{mmol}$ ) was used instead of ND. The pure product was isolated as a white solid. Yield: $77 \%(0.16 \mathrm{~g}) .{ }^{1} \mathrm{H}$ NMR $\left(400 \mathrm{MHz}, d_{6}\right.$ DMSO): $\delta 8.59(\mathrm{~d}, 1 \mathrm{H}, J=4.90 \mathrm{~Hz}), 8.49(\mathrm{~d}, 1 \mathrm{H}, J=4.92 \mathrm{~Hz})$, $8.23-8.20(\mathrm{~m}, 6 \mathrm{H}), 7.78(\mathrm{~d}, 1 \mathrm{H}, J=5.00 \mathrm{~Hz}), 7.69(\mathrm{~d}, 1 \mathrm{H}, J=$ $4.91 \mathrm{~Hz}), 7.58-7.42(\mathrm{~m}, 14 \mathrm{H}), 2.85(\mathrm{~s}, 3 \mathrm{H}), 2.83$ (s, 3H), $2.80(\mathrm{~s}$, $3 \mathrm{H}) .{ }^{13} \mathrm{C} \mathrm{NMR}\left(100 \mathrm{MHz}, \mathrm{CDCl}_{3}\right): \delta 165.79,165.75,165.51$, $161.48,161.04,153.20,152.82,152.69,143.43,143.32,143.12$, $141.23,140.46,140.25,139.94,137.32,136.68,136.52,129.65$, $129.46,129.29,128.71,128.67,128.60,127.72,127.65,127.62$, 125.39, 124.88, 17.55, 17.47. FAB-MS: calcd 732.24, $\mathrm{m} / \mathrm{z}=733.3$ $\left(\mathrm{M}+\mathrm{H}^{+}\right)$. Anal. Found (Calcd) for $\mathrm{C}_{45} \mathrm{H}_{33} \mathrm{AlN}_{6} \mathrm{O}_{3}: \mathrm{C}, 73.84$ (73.76); $\mathrm{H}, 4.37$ (4.54); N, 11.37 (11.47).

Synthesis of Tris(4-hydroxy-8-methyl-1,5-naphthyridinato)gallium $\left(\mathbf{G a m N D}_{3}\right)$. To a water solution $(7.2 \mathrm{~mL})$ were added $\mathbf{m N D}$ $(0.14 \mathrm{~g}, 0.87 \mathrm{mmol})$ and gallium chloride $(0.06 \mathrm{~g}, 0.34 \mathrm{mmol})$. The reaction mixture was heated and stirred at $\sim 40{ }^{\circ} \mathrm{C}$. An excess amount of potassium acetate was added to the solution to change the solution acidity from $\mathrm{pH} 3-4$ to $\mathrm{pH} 7-8$. During the reaction (ca. $1 \mathrm{~h}$ ), the formation of a milky white solid emitting blue fluorescence was observed. After cooling, the reaction solution was filtered to isolate the white solid. After washing with water, the solid was vacuum-dried and finally subjected to zone-temperature sublimation. The pure product was isolated as a white solid. Yield: $67 \%(0.11 \mathrm{~g}) .{ }^{1} \mathrm{H}$ NMR (400 MHz, $\left.\mathrm{CDCl}_{3}\right): \delta 8.70(\mathrm{~d}, 3 \mathrm{H}, J=$ $5.36 \mathrm{~Hz}), 8.62(\mathrm{~d}, 1 \mathrm{H}, J=4.83 \mathrm{~Hz}), 8.57(\mathrm{~d}, 1 \mathrm{H}, J=4.90 \mathrm{~Hz})$, $7.54(\mathrm{~d}, 1 \mathrm{H}, J=4.80 \mathrm{~Hz}), 7.46(\mathrm{~d}, 1 \mathrm{H}, J=4.71 \mathrm{~Hz}), 7.31(\mathrm{~d}, 1 \mathrm{H}$, $J=4.78 \mathrm{~Hz}), 7.27(\mathrm{~d}, 1 \mathrm{H}, J=4.89), 6.96(\mathrm{~d}, 1 \mathrm{H}, J=5.37 \mathrm{~Hz})$, $6.93(\mathrm{~d}, 1 \mathrm{H}, J=5.42 \mathrm{~Hz}), 6.92(\mathrm{~d}, 1 \mathrm{H}, J=5.36 \mathrm{~Hz}), 2.84(\mathrm{~s}, 3 \mathrm{H})$, $2.80(\mathrm{~s}, 3 \mathrm{H}), 2.78(\mathrm{~s}, 3 \mathrm{H}) .{ }^{13} \mathrm{C} \mathrm{NMR}\left(100 \mathrm{MHz}, \mathrm{CDCl}_{3}\right): \delta 165.18$, $164.98,164.74,154.43,153.96,153.51,153.04,153.00,143.89$, $143.81,143.41,143.15,141.22,136.08,135.45,135.34,125.23$, $125.14,124.71,109.61,109.51,108.97,17.95,17.85$. FAB-MS: calcd 546.09, $\mathrm{m} / \mathrm{z}=547.0\left(\mathrm{M}+\mathrm{H}^{+}\right)$. Anal. Found $(\mathrm{Calcd})$ for $\mathrm{C}_{27} \mathrm{H}_{21} \mathrm{GaN}_{6} \mathrm{O}_{3}$ : C, 59.03 (59.26); H, 4.00 (3.87); N, 15.09 (15.36).

Synthesis of Tris(4-hydroxy-2,8-dimethyl-1,5-naphthyridinato)gallium ( GammND $\left._{3}\right)$. This compound was synthesized in the same manner as $\mathbf{G a m N D}_{\mathbf{3}}$, except that $\mathbf{~ m m N D}(0.60 \mathrm{~g}, 3.4 \mathrm{mmol})$ was used instead of $\mathbf{m N D}$. The pure product was isolated as a white solid. Yield: $83 \%$ (0.56 g). ${ }^{1} \mathrm{H}$ NMR $\left(400 \mathrm{MHz}, \mathrm{CDCl}_{3}\right): \delta 8.51$ $(\mathrm{d}, 1 \mathrm{H}, J=4.83 \mathrm{~Hz}), 8.48(\mathrm{~d}, 1 \mathrm{H}, J=4.86 \mathrm{~Hz}), 7.45(\mathrm{~d}, 1 \mathrm{H}, J=$ $4.78 \mathrm{~Hz}), 7.38(\mathrm{~d}, 1 \mathrm{H}, J=4.90 \mathrm{~Hz}), 7.23(\mathrm{~d}, 1 \mathrm{H}, J=4.89 \mathrm{~Hz})$, $7.15(\mathrm{~d}, 1 \mathrm{H}, J=4.90 \mathrm{~Hz}), 6.83-6.82(\mathrm{~m}, 3 \mathrm{H}), 2.80(\mathrm{~s}, 3 \mathrm{H}), 2.77$ $(\mathrm{s}, 3 \mathrm{H}), 2.75(\mathrm{~s}, 3 \mathrm{H}), 2.61(\mathrm{~s}, 3 \mathrm{H}), 2.59(\mathrm{~s}, 6 \mathrm{H}) .{ }^{13} \mathrm{C}$ NMR $(100$ $\left.\mathrm{MHz}, \mathrm{CDCl}_{3}\right): \delta 164.63,164.56,164.36,163.94,163.40,163.33$, $152.32,151.88,143.31,143.25,142.20,142.00,140.07,135.02$, $134.38,134.26,125.10,124.96,124.62,109.57,109.32,108.88$, 26.31, 17.80, 17.71. FAB-MS: calcd 588.14, $\mathrm{m} / \mathrm{z}=589.0\left(\mathrm{M}+\mathrm{H}^{+}\right)$. Anal. Found (Calcd) for $\mathrm{C}_{30} \mathrm{H}_{27} \mathrm{GaN}_{6} \mathrm{O}_{3}$ : C, 61.50 (61.14); H, 4.63 (4.62); N, 14.17 (14.26).

Synthesis of Tris(4-hydroxy-8-dimethyl-2-phenyl-1,5-naphthyridinato)gallium (GampND $\mathbf{G}_{3}$ ). This compound was synthesized in the same manner as $\mathbf{G a m N D}$, except that mpND (0.20 g, 8.5 $\mathrm{mmol}$ ) was used instead of $\mathbf{m N D}$. The pure product was isolated as a white solid. Yield: $69 \%$ (0.15 g). $\left.{ }^{1} \mathrm{H} \mathrm{NMR} \mathrm{(400} \mathrm{MHz,} \mathrm{CDCl}_{3}\right)$ : $\delta 8.62(\mathrm{~d}, 1 \mathrm{H}, J=4.88 \mathrm{~Hz}), 8.59(\mathrm{~d}, 1 \mathrm{H}, J=4.88 \mathrm{~Hz}), 8.15-8.12$ $(\mathrm{m}, 6 \mathrm{H}), 7.53-7.40(\mathrm{~m}, 14 \mathrm{H}), 7.33(\mathrm{~d}, 1 \mathrm{H}, J=5.04 \mathrm{~Hz}), 7.30(\mathrm{~d}$, $1 \mathrm{H}, J=4.96 \mathrm{~Hz}), 2.93(\mathrm{~s}, 3 \mathrm{H}), 2.92(\mathrm{~s}, 3 \mathrm{H}), 2.86(\mathrm{~s}, 3 \mathrm{H}) .{ }^{13} \mathrm{C}$ NMR $\left(100 \mathrm{MHz}, \mathrm{CDCl}_{3}\right): \delta 165.42,165.31,165.13,161.13,160.78$, $160.70,153.50,153.15,153.11,143.63,143.59,142.77,142.62$, $140.66,140.39,140.19,139.91,135.45,134.82,134.70,129.64$, $129.46,129.32,128.69,128.67,128.60,127.69,128.61,125.38$, 125.24, 124.87, 106.99, 106.61, 106.24, 17.73, 17.65. FAB-MS: calcd 774.19, $\mathrm{m} / \mathrm{z}=775.2\left(\mathrm{M}+\mathrm{H}^{+}\right)$. Anal. Found (Calcd) for $\mathrm{C}_{45} \mathrm{H}_{33} \mathrm{GaN}_{6} \mathrm{O}_{3}$ : C, 69.80 (69.69); H, 4.27 (4.29); N, 10.72 (10.84).

Synthesis of Tris(4-hydroxy-8-methyl-1,5-naphthyridinato)indium $\left.(\mathbf{I n m N D})_{3}\right)$. To a water solution $(7.2 \mathrm{~mL})$ were added $\mathbf{m N D}$ $(0.15 \mathrm{~g}, 0.94 \mathrm{mmol})$ and indium chloride $(0.07 \mathrm{~g}, 0.32 \mathrm{mmol})$. The reaction mixture was stirred and heated at reflux temperature. An excess amount of potassium acetate was added to the solution to change the solution acidity from $\mathrm{pH} \mathrm{3-4} \mathrm{to} \mathrm{pH} 7-8$. During the reaction (ca. $1 \mathrm{~h}$ ), the formation of a milky white solid was observed. However, the blue fluorescence from such a precipitate was barely discernible. After the removal of water by vacuum distillation, the resulting solid was subjected to Soxhlet extration by dichloromethane for $24 \mathrm{~h}$. The extracted dichloromethane solution was evaporated until dryness, and the solid residue was further purified by zone-temperature sublimation. The pure product was isolated as an off-white solid. Yield: $76 \%(0.14 \mathrm{~g}) .{ }^{1} \mathrm{H}$ NMR $(400 \mathrm{MHz}$, $\left.\mathrm{CDCl}_{3}\right): \delta 8.67(\mathrm{~d}, 3 \mathrm{H}, J=5.40 \mathrm{~Hz}), 8.33(\mathrm{~d}, 3 \mathrm{H}, J=4.80 \mathrm{~Hz})$, $7.51(\mathrm{dd}, 3 \mathrm{H}, J=4.79 \mathrm{~Hz}, J=0.71 \mathrm{~Hz}), 6.95(\mathrm{~d}, 3 \mathrm{H}, J=5.41$ $\mathrm{Hz}), 2.83$ (s, 9H). ${ }^{13} \mathrm{C} \mathrm{NMR}\left(100 \mathrm{MHz}, \mathrm{CDCl}_{3}\right): \delta 165.73,153.71$, 153.68, 144.30, 144.22, 136.46, 125.04, 110.75, 18.23. FAB-MS: calcd 592.07, $\mathrm{m} / \mathrm{z}=593.0\left(\mathrm{M}+\mathrm{H}^{+}\right)$. Anal. Found $($Calcd $)$for $\mathrm{C}_{27} \mathrm{H}_{21} \mathrm{InN}_{6} \mathrm{O}_{3}$ : C, 54.79 (54.75); H, 3.46 (3.57); N, 14.07 (14.19).

Synthesis of Tris(4-hydroxy-2,8-dimethyl-1,5-naphthyridinato)indium ( $\left(\mathbf{n m m} \mathbf{N D}_{3}\right)$. This compound was synthesized in the same manner as InmND 3 , except that $\mathbf{m m N D}(0.17 \mathrm{~g}, 0.98 \mathrm{mmol})$ was used instead of $\mathbf{m N D}$. The pure product was isolated as an 
off-white solid. Yield: $81 \%$ (0.17 g). ${ }^{1} \mathrm{H}$ NMR (400 MHz, $\mathrm{CDCl}_{3}$ ): $\delta 8.22(\mathrm{~d}, 3 \mathrm{H}, J=4.80 \mathrm{~Hz}), 7.43(\mathrm{dd}, 3 \mathrm{H}, J=4.82 \mathrm{~Hz}, J=0.68$ $\mathrm{Hz}), 6.84$ (s, 3H), 2.79 (s, 9H), 2.53 (s, 9H). ${ }^{13} \mathrm{C} \mathrm{NMR}(100 \mathrm{MHz}$, $\left.\mathrm{CDCl}_{3}\right): \delta 165.19,163.02,152.57,143.74,143.04,135.36,124.89$, 110.57, 26.15, 18.04. FAB-MS: calcd 634.12, $\mathrm{m} / \mathrm{z}=635.1$ $\left(\mathrm{M}+\mathrm{H}^{+}\right)$. Anal. Found (Calcd) for $\mathrm{C}_{30} \mathrm{H}_{27} \mathrm{InN}_{6} \mathrm{O}_{3}: \mathrm{C}, 56.49$ (56.80); $\mathrm{H}, 4.24$ (4.29); N, 12.96 (13.25).

Synthesis of Tris(4-hydroxy-8-dimethyl-2-phenyl-1,5-naphthyridinato)indium (InmpND $\left.\mathbf{I}_{3}\right)$. This compound was synthesized in the same manner as $\mathbf{I n m} \mathbf{N D}_{\mathbf{3}}$, except that mpND $(0.50 \mathrm{~g}, 2.1$ mmol) was used instead of $\mathbf{m N D}$. However, the precipitate formed during the reaction was observed for blue fluorescence, and it was isolated by filtration. After washing with water, the solid was vacuum-dried and finally subjected to zone-temperature sublimation. The pure product was isolated as an off-white solid. Yield: $51 \%$ $(0.30 \mathrm{~g}) .{ }^{1} \mathrm{H} \mathrm{NMR}\left(400 \mathrm{MHz}, \mathrm{CDCl}_{3}\right): \delta 8.34(\mathrm{~d}, 3 \mathrm{H}, J=4.80$ $\mathrm{Hz}), 8.15-8.12(\mathrm{~m}, 6 \mathrm{H}), 7.53-7.51(\mathrm{~m}, 6 \mathrm{H}), 7.49-7.40(\mathrm{~m}, 9 \mathrm{H})$, $2.91(\mathrm{~s}, 9 \mathrm{H}) .{ }^{13} \mathrm{C} \mathrm{NMR}\left(100 \mathrm{MHz}, \mathrm{CDCl}_{3}\right): \delta 165.99,160.24$, 153.78, 144.04, 143.62, 140.05, 135.77, 129.44, 128.63, 127.57, 125.15, 107.86, 17.99. MOLDI-TOF MS: calcd 820.17, $\mathrm{m} / \mathrm{z}=$
$821.15\left(\mathrm{M}+\mathrm{H}^{+}\right)$. Anal. Found (Calcd) for $\mathrm{C}_{45} \mathrm{H}_{33} \mathrm{InN}_{6} \mathrm{O}_{3}: \mathrm{C}, 65.78$ (65.86); H, 3.95 (4.05); N, 10.26 (10.24).

Acknowledgment. This research was supported in part by the National Science Council of Taiwan, Academia Sinica, National Taiwan Normal University, National Chung Cheng University, National Taiwan University, and National Chiao Tung University.

Supporting Information Available: The synthesis and structural characterization data of chelating ligands, ND, mND, mmND, mpND, and their precursors are described. DSC thermograms of $\mathbf{A l m p N D}_{\mathbf{3}}, \mathbf{G a m p N D}$, and $\mathbf{I n m p N D}_{\mathbf{3}}$ (Figure S1); EL characteristics (Figure S2) and data (Table S1) of nondoped $\mathrm{GamND}_{3}, \mathrm{GammND}_{3}, \mathrm{InmND}_{3}$, or $\mathbf{I n m m N D}$ OLEDs; absorption and photoluminescence spectra of $\mathbf{A l m N D}_{\mathbf{3}}$ and rubrene as well as their solution fluorescence images (Figure S3) are given. The crystallographic information is listed in Table $\mathrm{S} 2$ and file (.cif) also given for $\mathbf{A} \mathbf{I N D}_{3} \cdot \mathrm{CH}_{2} \mathrm{Cl}_{2}$. This material is available free of charges via the Internet at http://pubs.acs.org.

JA807284E 